The following article was published as: Wu G, Khodaparast $L$, Khodaparast $L$, De Vleeschouwer M, Housmans J, Houben B, Schymkowitz J, Rousseau F. Investigating the mechanism of action of aggregation-inducing antimicrobial Peptins. Cell Chem Biol. 2020 Dec 31:S2451-9456(20)30517-1.

doi: 10.1016/j.chembiol.2020.12.008.

Epub ahead of print. PMID: 33434517.

\title{
Investigating the mechanism of action of aggregation-inducing antimicrobial Pept-ins
}

Guiqin $\mathrm{Wu}^{1,2}$, Laleh Khodaparast ${ }^{1,2}$, Ladan Khodaparast ${ }^{1,2}$, Matthias De Vleeschouwer ${ }^{1,2}$, Joëlle Housmans ${ }^{1,2}$, Bert Houben $^{1,2}$, Joost Schymkowitz ${ }^{1,2,3, *}$, and Frederic Rousseau ${ }^{1,2,{ }^{*}}$

${ }^{1}$ Switch Laboratory, VIB Center for Brain and Disease Research, Herestraat 49, 3000 Leuven, Belgium.

${ }^{2}$ Switch Laboratory, Department of Cellular and Molecular Medicine, KU Leuven, Herestraat 49, 3000 Leuven, Belgium.

${ }^{3}$ Lead contact

* Correspondence: joost.schymkowitz@kuleuven.be or frederic.rousseau@kuleuven.be 


\section{Summary}

Aggregation can be selectively induced by aggregation-prone regions (APRs) contained in the target proteins. Aggregation inducing antimicrobial peptides (Pept-ins) contain homologous sequences to APRs of target proteins and exert their bactericidal effect by causing aggregation of a large number of proteins. To better understand the mechanism of action of Pept-ins and the resistance mechanisms, we analysed the phenotypic, lipidomic, transcriptomic as well as genotypic changes of laboratory derived Pept-in-resistant E. coli mutator cells. The analysis showed that Pept-in resistance mechanism is dominated by a decreased Pept-in uptake, both in laboratory derived mutator cells and clinical isolates. Our data indicates that Pept-in uptake involves the electrostatic attraction between Pept-in and bacterial membrane and follows a complex mechanism potentially involving many transporters. Furthermore, it seems more challenging for bacteria to become resistant towards Pept-ins which are less dependent on electrostatic attraction for uptake, suggesting future Pept-ins should be selected for this property.

\section{Keywords}

Protein aggregation; aggregation prone region; aggregation inducing antimicrobial peptides; electrostatic attraction; antimicrobial peptide uptake

\section{Introduction}

Antibiotic resistance is an emerging global health issue. It can cause failure of both the treatment and the prevention of bacterial infectious diseases, which could further increase the risk of performing medical procedures and raise the cost for health care (Sommer et al., 2017). Development of novel antibiotic classes is urgently needed to address this increasingly pressing issue. We have shown a promising antibacterial strategy by disrupting bacterial homeostasis achieved via inducing widespread bacterial protein aggregation using synthetic amyloidogenic peptides (Bednarska et al., 2016a; Khodaparast et al., 2018).

Protein aggregation is a sequence-specific mode of protein self-interaction whereby misfolded proteins polymerise into either amorphous aggregates or amyloid fibrils typically composed of a single protein (Yoshimura et al., 2012). During the initial nucleation phase of protein aggregation, a slow and thermodynamically unfavourable process, stable seeds are formed by rearranging misfolded protein structures into a series of $\beta$-strands. Upon the formation of seeds, aggregation enters the elongation phase during which preformed seeds rapidly grow by incorporating additional protein units into the polymers (Soto and Pritzkow, 2018). Thus, protein aggregation can be accelerated by addition of preformed seeds, the seeding efficiency depends critically on the sequence homology between the seeds and the target proteins (Eisenberg and Jucker, 2012). Protein aggregation is mediated by short aggregation-prone regions (APRs), which on average occur at least once every 100 amino acids of almost all proteins (Rousseau, Serrano and Schymkowitz, 2006). Most APRs are unique in a given proteome, thus, it is possible to specifically induce aggregation of a target protein by using preformed seeds of a synthetic peptide (also called Pept-in) encoding the APR of the target protein (Betti et al., 
2016; Gallardo et al., 2016). However, a minority of redundant APRs (which contain the same or homologous sequence) can be found in several or sometimes many different proteins (Khodaparast et al., 2018). This offers a novel antibacterial approach which induces the aggregation of bacterial target proteins by the preformed seeds of Pept-ins encoding the redundant APR of these target proteins. This results in widespread aggregation of many proteins in bacteria, which in turn can lead to the disruption of proteostaisis and thus eventually to bacterial cell death (Bednarska et al., 2016a; Khodaparast et al., 2018). Owing to the unique mode of action which involves the aggregation of hundreds of proteins, we observed no resistance development during subculturing experiments in Escherichia coli (E. coli) or Staphylococcus aureus (Bednarska et al., 2016a; Khodaparast et al., 2018). Taken together, disrupting proteostasis by targeting the redundant APRs and inducing widespread protein aggregation using synthetic peptides shows great therapeutic potential.

Although the main mode of action of these aggregation-inducing antimicrobial Pept-ins is achieved through inducing the aggregation of a massive amount of bacterial proteins, the mechanism of action remains to be investigated which is crucial for successful antimicrobial Pept-in development, efficacy improvement and toxicity minimisation for mammalian cells. Their potential resistance mechanisms need to be investigated as well, which are valuable for optimising Pept-in-design and delaying resistance occurrence (Martínez, Baquero and Andersson, 2007). To better understand their mechanism of action and potential resistance mechanisms, we generated Pept-in-resistant bacteria through laboratory evolution experiments using the E. coli XL1-Red hypermutator strain (Greener, Callahan and Jerpseth, 1997; Barrick et al., 2009). The reasons for using a hypermutator strain were that wild-type bacteria showed no resistance build-up to Pept-ins and hypermutator strains could allow a more rapid resistance acquisition towards these Pept-ins (Greener, Callahan and Jerpseth, 1997). Hypermutable strains have been frequently identified in clinical settings and are suitable backgrounds for studying the evolution of acquired resistance genes (Woodford and Ellington, 2007). XL1-Red cells have a 5000fold higher mutation rate than the wild-type and generate random mutations at the genomic DNA. (Greener, Callahan and Jerpseth, 1997).

We found that resistance development towards Pept-in P2 is very slow and no cross-resistance between Peptins was observed. Phenotypic studies showed that the resistance mechanism is mostly caused by reduced P2 accumulation within bacteria, resulting mainly from a decreased cellular uptake. P2-resistant cells show a decreased negative charge in the membrane and were enriched for coding mutations in protein and peptide transporters, which appear to collectively contribute to the decreased P2 uptake. Further analysis of P2 resistant clinical isolates showed that limiting P2 uptake is also associated with P2-resistance mechanism in these clinical isolates. These P2 resistant clinical isolates exhibited less negative charge at membrane as well, confirming the importance of electrostatic attraction for P2 uptake across different bacteria strains.

\section{Results}

Resistance development towards aggregation inducing Pept-ins is slow, even in the mutator strain 
To study the potential resistance development of Pept-ins in XL1-Red cells, we performed the classic adaptive laboratory evolution experiment for the following conditions: vehicle (PBS), ampicillin (AMP), P33 and P2. P2 and P33 are previously identified Pept-ins and each encodes a distinct bacterial APR fragment (Table 1) (Khodaparast et al., 2018). To generate efficient aggregation seeds, these Pept-ins employ a tandem repeat design which includes two identical APRs flanked by three solubilising arginine residues (also called gatekeepers) and linked by a single proline (Bednarska et al., 2016b). Three independent bacterial populations were evolved for 27 days in parallel for each condition with a daily treatment at 1/3 MIC concentration. The most significant MIC increase was observed for AMP: from $3.25 \mu \mathrm{g} / \mathrm{mL}$ to $400 \mu \mathrm{g} / \mathrm{mL}$ (Figure 1A). The MIC increase observed for Pept-ins was slower compared to AMP, while P2 MIC increased from $6.25 \mu \mathrm{g} / \mathrm{mL}$ to $200 \mu \mathrm{g} / \mathrm{mL}$ (Figure 1B), P33 MIC raised only from $3.12 \mu \mathrm{g} / \mathrm{mL}$ to $6.25 \mu \mathrm{g} / \mathrm{mL}$ (Figure 1C). The MIC for either AMP, P2 or P33 did not change in vehicle treated cells (Figure 1A-C), confirming that the observed antibiotic resistance is induced due to the antibiotic pressure, not the random mutations generated by the high mutation rate of XL1-Red cells.

Increased concentration of antibiotic treatment elevates mutation rates (Pal et al., 2007), which can accelerate resistance acquisition. Correspondingly, XL1-Red cells became resistant towards all antibiotics at a faster rate when the daily treatment was increased to 2/3 MIC concentration (Figure 1D-F). However, it is worth noting that Pept-in MIC increase still occurred at a much slower rate compared to AMP. P33 MIC raised only from 3.25 $\mu \mathrm{g} / \mathrm{mL}$ to $12.5 \mu \mathrm{g} / \mathrm{mL}$ even after 27 days of continuous treatment (Figure 1E). These results further confirm that Pept-in resistance acquisition is very difficult, especially for P33. Antibiotic treatment at both 1/3 MIC (Figure 1G) and 2/3 MIC (Figure 1H) led to a decreased growth rate with a longer lag phase and a lower cell density at the stationary phase, indicating a fitness cost associated with the burden of the antibiotic-resistant and/or random mutations (Lee et al., 2010).

\section{Unique collateral-sensitivity and cross-resistance profile due to Pept-in resistance}

We examined whether Pept-in-resistance development caused collateral-sensitivity or cross-resistance towards other antibiotics, a phenomenon which is frequently observed during the evolution of antibiotic resistance (Jahn et al., 2017; Lázár et al., 2018; Nichol et al., 2019). For this purpose, we determined the susceptibility of 14 antibiotics from six different categories against strains derived from the end of the evolution experiment (Table S2). Pept-in-resistant strains showed collateral-sensitivity towards RNA synthesis inhibitor, protein synthesis inhibitors, fatty acid synthesis inhibitors and cell division inhibitors (Figure 2C-D). However, they developed cross-resistance towards positively charged antibiotics, with a 3 to 5-fold MIC increase towards membranedisrupting cationic antimicrobial peptides (CAMPs) and a 2-fold MIC increase towards the aggregation-inducing Pept-ins (Figure 2C-D). Notably, the Pept-in resistance associated collateral-sensitivity and cross-resistance profiles were not observed in vehicle- (Figure 2A) or AMP- (Figure 2B) evolved strains.

The cross-resistance towards positively charged antibiotics observed in Pept-in-resistant strains suggests that a decreased negative charge in the membrane could play a role in Pept-in resistance mechanism. To verify this hypothesis, we determined the membrane surface charge of evolved strains by measuring the binding of the 
cationic FITC-labelled poly-L-lysine (FITC-PLL) to bacterial membrane, which is often used to quantify the negative charge at the membrane (Spohn et al., 2019). Compared to ancestors, vehicle- and AMP-evolved strains exhibited similar levels of FITC median fluorescent intensity (MFI), whereas P2-resistant strains showed significantly lower levels of FITC MFI (Figure 2E-F). Although P33-resistant strains demonstrated no significant change in the level of FITC MFI (Figure 2E), the histogram of FITC-fluorescence distribution demonstrated that a subpopulation of P33-derived strains showed less binding to FITC-PLL. This result confirms that Pept-in-resistant strains have a reduced negative charge at the membrane, which this is more evident in P2-resistant strains.

\section{Impaired $\mathrm{P} 2$ uptake dominates $\mathrm{P} 2$ resistance}

Preventing access to drug targets is a common antibiotic resistance mechanism (Blair et al., 2015). As P2 exerts its bactericidal effect by inducing protein aggregation co-translationally in the cytoplasm (Khodaparast et al., 2018), we next compared P2 accumulation using FITC-labelled P2 in the ancestor strains, and in strains under different treatment from day 13 as well as day 27. While P2-derived cells from day 13 and P33-derived cells from day 27 showed a 2-fold MIC increase compared to ancestors, P2-derived cells from day 27 showed 30-fold MIC increase, the rest had the same MIC as the ancestors. The rate (Figure 3A) and the amount (Figure 3B) of FITC-accumulation, as well as the time-dependent killing (Figure $3 C$ ) of evolved cells with unaltered P2 MIC were similar to ancestors, however, all three showed a decrease in evolved cells which had 2-fold P2 MIC increase (P33- and P2-derived cells from day 27 and 13, respectively). This reduction of FITC-accumulation and decrease in the rate of time-dependent killing was most evident in P2-derived strains from day 27 (Figure 3A-C). These results show that bacteria enhance their $\mathrm{P} 2$ resistance level by continuously evolving and strengthening their ability to decrease the intracellular accumulation of the Pept-in. FITC-P2 accumulated mainly intracellularly at the polar regions in ancestor cells, whereas only a very faint FITC signal was observed around the membrane region for P2-resistant strains after $2 \mathrm{~h}$ treatment (Figure 3D). These results further confirm that preventing the access of $\mathrm{P} 2$ to its target proteins is crucial for the resistance mechanism.

We next determined whether the decreased P2 accumulation was due to decreased P2 uptake and/or increased efflux by conjugating P2 with the fluorescein diacetate isothiocyanate (FITC-2DA). FITC-2DA is non-fluorescent and can be hydrolysed to fluorescent FITC in live cells by cellular esterases, but not in dead cells due to the decreased or diminished esterase activity (Wang et al., 2011; Mao et al., 2020). P2 efflux activity was determined by measuring FITC intensity in the supernatant during the first $2 \mathrm{~h}$ after FITC-2DA-P2 treatment, since ancestors showed the most significant increase of $\mathrm{P} 2$ accumulation in the initial $2 \mathrm{~h}$ upon receiving treatment whereas $\mathrm{P} 2$ resistance cells maintained P2 accumulation at a very low level (Figure 3B). No significant difference was observed regarding P2 efflux activity in P2-resistant cells in the first $2 \mathrm{~h}$ after FITC-2DA-P2 treatment (Figure 3E). This result suggests that the decreased P2 accumulation in P2-resistant strains is mainly contributed by a decrease of P2 uptake. Although we observed an increase of FITC intensity in the supernatant after $6 \mathrm{~h}$ treatment for ancestors, vehicle-, P33- as well as P2-evolved strains, this could be contributed due to the lysis of bacterial cells which results in the subsequent leakage of esterase and already hydrolysed form of FITC-2DA-P2. 
Pept-ins targeting abundant APRs in bacteria cause misfolding and aggregation of a large number of proteins which accumulate in inclusion bodies (IBs) at the polar regions (Bednarska et al., 2016b; Khodaparast et al., 2018). These IBs can be stained with the amyloid-specific dye pFTAA which specifically binds to amyloid-like aggregates (Åslund et al., 2009). Upon $4 \mathrm{~h}$ treatment of P2 at $6.25 \mu \mathrm{g} / \mathrm{mL}$, IB formation was observed in almost all ancestor cells, but only in a few P2-resistant cells (Figure 3F). However, all P2-resistant cells formed IBs upon $\mathrm{P} 2$ treatment at $200 \mu \mathrm{g} / \mathrm{mL}$ (Figure 3F) or by P33 treatment at $6.5 \mu \mathrm{g} / \mathrm{mL}$ (Figure 3F). This data demonstrates that Pept-ins are able to induce protein aggregation once taken up into P2-resistant cells, suggesting that interfering with IB formation does not play an important role in the P2 resistance mechanism. This may be due to the high number of P2 target proteins (Khodaparast et al., 2018) and the evolutionarily more conserved APRs of target proteins (Bednarska et al., 2016b).

Lipid-peptide interaction plays an important role in AMP mediated killing and internalisation, pathogens frequently modify their lipidomic profile to increase resistance towards antibiotics (Zhang and Rock, 2008). Thus, we determined whether P2-resistant strains modified the lipidome for gaining resistance towards P2. In general, the percentage of each main lipid class in P2-resistant strains showed no significant change from ancestors or underwent similar changes as in vehicle treated cells (Figure $\mathbf{3 G}$ ). In some cases, the positive charge of AMPs induces clustering of anionic lipids on the membrane and subsequently promotes the pore formation of bacterial membrane (Epand et al., 2010). However, we did not observe significant changes in the anionic lipid classes (PG and $\mathrm{CL}$ ) in P2-resistant strains (Figure $3 \mathbf{H}$ ). Bacteria can adopt a more rigid membrane by decreasing the percentage of unsaturated lipid class, which consequently makes the membrane harder for antibiotics to penetrate (Khondker et al., 2019). However, P2-resistant strains exhibited no alteration in the percentage of unsaturated lipid classes (Figure 31). These results collectively suggest that P2 translocation into bacteria or P2mediated killing does not dependent on lipid-peptide interaction.

\section{Altered gene expression contributes to the decreased membrane negative charge}

Having observed that the P2 resistance mechanism is mainly caused by a decreased uptake and a decreased negative charge at the membrane, we next sought to investigate the molecular mechanism of P2 resistance by comparing the transcriptomic profiles of P2-resistant strains to ancestors.

The expression level of 462 and 286 genes were significantly downregulated and upregulated, respectively. These affected genes were analysed by ClueGO plug-in of Cytoscape to identify statistically enriched biological pathways (Bindea et al., 2009). The analysis revealed that many metabolic pathways were downregulated (Figure 4A). Since these downregulated metabolic pathways are not overlapping with the biological pathways enriched from the proteins identified from P2-induced IBs (Khodaparast et al., 2018), they are likely not associated with $\mathrm{P} 2$-resistance, but rather contributing to the slower growth rate observed in P2-resistant strains. Furthermore, 35 genes involved in translation were downregulated (Figure 4A) which were also enriched in the peptide-induced inclusion bodies ${ }^{2,3}$. To further determine the effect of a slower translation elongation rate on Pept-in efficacy, we compared the amount of IB formation upon Pept-in treatment between the wild-type E. coli 
and the $\mathrm{CH} 184$ mutant strain (with a elongation rate of 14 and 6 amino acid per second, respectively) (Proshkin, Rahmouni and Mironov, 2020). The data showed that a significantly higher amount of IB was induced in CH184 mutant strain upon both P2 treatment (Figure S1A-B) and P33 treatment (Figure S1C-D) compared to the wildtype. This suggests that the slower elongation rate in $\mathrm{CH} 184$ could lead to a prolonged exposure of unfolded proteins during translation, rendering these proteins more prone to aggregation in the presence of Pept-ins and thus making CH184 more susceptible towards Pept-ins. Indeed, although CH184 showed a similar P2 MIC as the wild-type, it showed a 2-fold lower P33 MIC compared to the wild-type (Table S1). Collectively, these results suggest that reducing ribosome biogenesis and translational events, but not slowing down elongation rate, could be beneficial for surviving Pept-in-imposed stress, albeit only to a very small degree.

P2-resistant strains showed a reduced negative charge at the membrane, correspondingly, they exhibited altered gene expression in two pathways which are involved in membrane charge modification (Figure 4B). The first being upregulated expression of $\operatorname{arnBCADTEF}$ operon. The arnBCADTEF operon encodes proteins which mediate the transfer of 4-aminoara-binose (L-Ara4N) to lipid A and thereby masking the negatively charged phosphate groups. This modification decreases the net charge of lipid A to zero, which is the most common and effective modification to decrease the negative charge at the membrane (Olaitan, Morand and Rolain, 2014). The second pathway concerns downregulated yeiO (IpxT) expression and upregulated pmrR expression. LpxT generates di-phosphorylated lipid A and thereby increasing LPS negative charge, while PmrR has been shown to be the inhibitor of LpxT (Manuscript, 2013; Simpson and Trent, 2019). Thus, PmrR mediated LpxT suppression is also involved in decreasing the negative charge at the membrane in P2-resistant strains. This data collectively shows that P2-resistant strains decrease the negative charge at the membrane by increasing ArnBCADTEF mediated L-Ara4N modification and inhibiting LpxT mediated phosphorylation of lipid A.

We observed downregulation of 20 transporter genes in P2 resistant cells (Table S3), BtuB and FadL have been reported to be involved in the uptake of hydrophobic molecules with high molecular weight (Sharma et al., 2007; Wiener and Horanyi, 2011), suggesting their potential role in P2-resistance mechanism. No downregulation of efflux pump was observed in P2-resistant cells, further supporting the hypothesis that P2 efflux does not play an important role in $\mathrm{P} 2$ resistance.

\section{Enriched transporter genes mutated in P2-resistant strains}

We performed whole genome sequencing of ancestors and strains from the end of the evolution experiment to elucidate the relationship between the phenotypic and transcriptomic profiles of P2-resistant strains. Before DNA extraction, we confirmed that the acquired antibiotic resistance was stable by growing a single colony overnight in the absence of antibiotics. The subsequent two nights a single colony from the previously grown culture was grown again in the absence of antibiotics, which did not result in any MIC change. Bacteria receiving antibiotic treatment at 2/3 MIC concentration for 16 days accumulated a higher number of both total mutations and total mutated genes than at 1/3 MIC concentration for 27 days (Figure 5A-B), suggesting that the increased mutation rate is beneficial for a faster adaptation to the antibiotic pressure. Although P33-evolved strains 
showed the least MIC increase compared to ampicillin- and P2-evolved strains, they had the highest number of mutated genes (Figure 5B). This data suggests that it is difficult to select P33-resistance mutations for a continuous increase in resistance, either due to either a high fitness cost or a less occurring frequency.

As synonymous mutations normally have a lower expected functional impact, we focused on the coding mutations in the subsequent analysis. To compare the distribution of coding mutations across $E$. coli genome under different treatments, we mapped the frequency and position of each coding mutation in the sequenced strains from the end of the evolution experiment for each treatment. Each treatment resulted the accumulation of a unique set of frequently occurring coding mutations at the end of the evolution (Figure $5 \mathrm{C}$ ), suggesting that cells selected distinct mutations for adapting to the corresponding antibiotic stress.

Because P2-evolved cells had fewer mutations when treated at 1/3 MIC concentration, we further sequenced 3 single colonies from day 13, day 18, day 21 and day 27 evolved from vehicle and P2 treatment, resulting in 12 colonies for each group. While P2 MIC was unchanged in vehicle-derived colonies $(6.25 \mu \mathrm{g} / \mathrm{mL})$, the MIC kept increasing under P2 treatment from day $13(25 \mu \mathrm{g} / \mathrm{mL})$ to day $18(50 \mu \mathrm{g} / \mathrm{mL})$, day $21(100 \mu \mathrm{g} / \mathrm{mL})$ and finally day $27(200 \mu \mathrm{g} / \mathrm{mL})$ (Figure 1C). Until day 21, on average a higher number of genes evolved coding mutations due to P2 treatment compared to vehicle treatment (Figure 5D). However, the number in vehicle treated strains surpassed the P2 treated strains (Figure 5D), which could be a result of loss of function at DNA repair pathways due to random mutations. Out of the 11 vehicle-derived colonies, the majority of the mutated genes occurred only in 1-2 colonies (Figure 5E), suggesting that the vehicle treatment led to the occurrence of random mutations which could not be fixed due to the absence of an evolutionary pressure. In contrast, P2 treatment led to the occurrence of both randomly mutated genes as well as accumulation of mutated genes occurring in more than 10 colonies out of the 14 colonies (Figure $5 \mathrm{E}$ ), providing evidence of positive selection in response to P2 treatment. Indeed, while 1425 genes exhibited coding mutations across the 12 vehicle-evolved strains, only 960 genes exhibited coding mutations across the 12 P2-evolved strains (Figure 5F). Furthermore, a higher number of genes had fixation of mutation across those 12 P2-derived strains (Figure 5F). Next, we analysed the genes which had fixation of mutation at day 13 and day 27 since they revealed higher MIC increase and more mutation fixation. Mutated genes were enriched in metabolic pathways due to vehicle treatment at day 13 and day 27

(Figure 5G). However, an enrichment of mutated genes for protein and peptide transportation due to P2 treatment was observed at day 13 , the number of which further increased at day 27 (Figure $\mathbf{5 H}$ ), suggesting these transporters could play a role in P2 uptake.

\section{Multiple pathways are required for the development of $\mathrm{P} 2$ resistance}

To determine which genes are responsible for P2 resistance, we determined P2 MIC for 120 single-gene knockout strains from the E. coli Keio knock-out collection (Baba et al., 2006). We selected these genes based on either one of the following three categories: (1) described in the literature as peptide uptake transporters, (2) downregulated expression, (3) under positive selection due to P2 treatment, with a dN/dS ratio above 1 (Kryazhimskiy and Plotkin, 2008). None of the single-gene deletions contributed to significant increase of P2 MIC, 
but 35 out of 120 single gene deletion led to a 2-fold increase in P2 MIC, and most of these genes are $A B C$ transporters (Table S4). This indicates a complex P2 uptake system, which is achieved via multi-pathways, such as cysteine uptake, dipeptide uptake and putrescine uptake pathways. The multiple-gene knockout of putrescine uptake system (Guerra et al., 2018), either potABCD or potFGHI, showed no P2 MIC increase compared to the wild-type (Table S4), suggesting that P2 uptake does not depend on one single system.

Clinical isolates of P2 resistant K. pneumonia and E. cloacae showed decreased P2 uptake and less negative charge at membrane

The analysis of laboratory-derived P2-resistant cells showed that Pept-in resistance mechanism is dominated by a decreased Pept-in uptake. To evaluate whether this Pept-in uptake-limiting resistance mechanism can be extrapolated to other strains, we compared P2 antimicrobial potency, uptake and IB inducing efficacy against different multi-drug resistant clinical isolates (E. cloacae 48, 51, 77 and $K$. pneumoniae).

While E. cloacae 48 were susceptible towards P2 (with a P2 MIC of $25 \mu \mathrm{g} / \mathrm{mL}$ ), E. cloacae 51, 77, and $K$. pneumoniae were resistant towards P2 which showed a P2 MIC above $100 \mu \mathrm{g} / \mathrm{mL}$ (Table 5). To determine whether P2 uptake was impaired in these P2-resistant clinical isolates, we compared P2 uptake using FITClabelled P2 in these four isolates. The SIM images confirmed that, when treated at $25 \mathrm{ug} / \mathrm{mL}$ for $2 \mathrm{~h}$, almost all cells showed P2 uptake for E. cloacae 48, whereas P2 uptake was only observed in a sub-population for E. cloacae 51, 77 and K. pneumoniae (Figure 6A). Quantification of FITC fluorescent intensity using microbeJ (Ducret, Quardokus and Brun, 2016) of bacteria which were FITC-positive demonstrated that the amount of P2 uptake was the highest for P2-susceptible isolate E. cloacae 48, whereas this was substantially lower for P2-resistant isolates, with K. pneumoniae showed the least amount of P2 uptake (Figure 6B). This data confirms that the clinically isolated multi-drug resistant isolates display a similar Pept-in uptake-limiting resistance mechanism as the laboratory-derived mutator cells. Correspondingly, less cells with protein aggregation events were observed for $E$. cloacae 51 and E. cloacae 77, while almost no cells with protein aggregation events were observed for $K$. pneumoniae (Figure 6A). The fluorescence intensity of protein aggregation dye HS169 in all P2-resistant isolates (Calvo-Rodriguez et al., 2019) were lower compared to the P2-susciptible E. cloacae 48 (Figure 6C). These results

confirm that the bactericidal effect of Pept-in is exerted intracellularly and rejecting Pept-in uptake increases the chance of surviving Pept-in treatment.

Since P2-resistant mutator cells demonstrated less negative charge at membrane, we determined whether the same phenomenon was observed in P2-resistant clinical isolates using FITC-PLL. Indeed, P2-resistant isolates demonstrated less binding towards FITC-PLL compared to P2-susceptible E. cloacae 48 (Figure 6D-E), indicating less negative charge at membrane of P2-resistant isolates. This data further proves our conclusion that the P2 uptake depends heavily on the electrostatic interaction between the positively charged P2 and the negatively charged bacterial membrane. Notably, the reduction of P2 uptake is not always proportional to the reduction 
of membrane charge (Figure 6B, 6E), agreeing with our conclusion that P2 uptake follows a complex mechanism potentially involving many transporters as we have shown using the mutator strain.

\section{Discussion}

To combat the increasingly urgent health issue imposed by antibiotic resistance, huge efforts are being devoted to investigate new platforms for novel antibiotic development (Czaplewski et al., 2016; Seiple et al., 2016; Richter et al., 2017; Khodaparast et al., 2018; Li et al., 2018; Tucker et al., 2018; Culp et al., 2020; Stokes et al., 2020). Although most antimicrobial agents are new classes in the preclinical phase, the clinical pipeline largely depends on modification of known antibiotic classes (Theuretzbacher et al., 2020). To guide the progression of novel aggregation-inducing Pept-ins into clinical development, here we investigated the potential resistant mechanisms and mechanism of action of previously reported Pept-in P2 and P33.

Our results indicate that the most efficient surviving mechanism against P2 consists of making sure P2 remains outside of the bacteria. This is most likely because of the swift and overwhelming effects of Pept-in-induced aggregation events once the peptide enters the cells. The positively charged arginine residues of P2 promote P2 interaction with the negatively charged bacterial membrane (Lázár et al., 2018). As a consequence of the electrostatic attraction between P2 and bacteria membrane, P2-resistant cells exhibited decreased membrane negative charge. It has been shown that CAMPs containing less positively charged amino acids tend to be less prone in eliciting resistance development (Spohn et al., 2019). Thus, future studies can be performed to explore whether P2 variants with decreased positive charge residues could delay resistance development. Internalisation of non-lytic peptide substrates can occur either in transporter-dependent (such as bac7, PR-39 (Runti et al., 2013)) or independent pathways (such as indolicidin and Buforin-2 (Cardoso et al., 2019)). P2resistant strains showed downregulation and enriched mutations of transporter genes, indicating that P2 uptake involves many transporters.

When looking at the mode of action of Pept-ins, we can speculate that bacteria may become resistant through other mechanisms in addition to preventing P2 from entering the bacteria. First of all, Pept-in-induced aggregation occurs co-translationally. Therefore, a reduction of ribosome biogenesis and translational events decreases the exposure of APRs and subsequently decreases the aggregation events, which could be beneficial for surviving these Pept-ins. Indeed, this is what was observed for P2 resistant strains. However, this hampering of translation is harmful for the bacteria themselves and they cannot block this process completely. As long as translation events still occur, Pept-ins can induce aggregation once they enter the cells. Secondly, P2 treatment induced the aggregation of hundreds of proteins which were enriched in diverse biological pathways. Therefore, becoming less dependent on these pathways could increase their chance of surviving P2 treatment. However, since a large number of biological pathways are involved, it is evolutionarily more difficult to completely abandon these pathways in order to survive P2. This also suggests that P2-mediated killing is not due to one single biological pathway, but rather the combined detrimental effects of all aggregated proteins. Furthermore, Pept-ins induce the aggregation of target proteins by first forming aggregating seeds which then interact with 
the homologous APRs of target proteins. Bacteria may mutate the APR of target proteins in order to skip the aggregation cascade. However, none of the homologous APR regions of P2 target proteins were mutated. This makes sense in view of the position of APRs deep inside the hydrophobic core of folded proteins (Ganesan, Siekierska and Schymkowitz, 2016), where random mutation rate is the lowest of any proteome. Moreover, we recently demonstrated that mutations that abrogate an APR are also likely to disrupt the folding of the native state and hence increase the aggregation in that way. Moreover, these Pept-ins have been designed to have multiple targets, so single mutation to abrogate an APR would constitute a particular selective advantage.

In general, aggregation inducing Pept-ins are less prone to induce resistance compared to ampicillin which is most likely related with their unique mode of action which involves a large number of target proteins. Further knowledge of the exact reason why P33 induced almost no resistance development even in the mutator cells can provide a guideline for the clinical development of Pept-in antibiotics which bacteria may not be able to become resistant to. The fact that P33-derived bacteria did not show a significant decrease of negative charge at the membrane and P33 remained to be active against P2-resistant cells suggest that P33 uptake are less dependent on the electrostatic attraction. This less-dependence on electrostatic attraction for P33 uptake could be contributing to the observation that bacteria have an increased difficulty to develop resistant against P33. Future studies should explore whether this rule can be applied to all Pept-in antibiotics or other CAMPs.

Despite the clear advantages of aggregation-inducing Pept-ins over conventional antibiotics, there are still limitations which need to be addressed in order to successfully translate Pept-ins into clinical therapeutic agents and to benefit patients. Efforts into optimising Pept-in structure design and formulation are required for Peptins to perform better than conventional antibiotics, to induce low systemic toxicity, to show sufficient stability both in vitro and in vivo, to exhibit increased resistance in proteolytic environment and increased absorption in the intestine. These improvements will enable Pept-ins to reach the clinical effectiveness and allow Pept-ins to be administrated orally which is regarded as the most preferred administration mode.

\section{Significance}

The clinical pipeline of antibiotic development mainly depends on the modification or combination therapies of existing antibiotics (Butler and Paterson, 2020), which does not address the threatening issue imposed by the rapid development of antibiotic resistance. Translation of preclinical antibacterial agents with true novel mode of action into clinical development phase and the market is required to have an actual clinical impact, which requires an extensive investigation regarding these novel antibiotic agents. To guide the progression of aggregation-inducing antimicrobial Pept-ins into clinical development, here we investigated the potential resistance mechanisms and mechanism of actions of previously reported Pept-in P2 and P33. The data showed that Pept-ins are less prone to induce resistance compared to ampicillin, especially for P33, even in the mutator bacteria. P2-resistant bacteria evolved widespread collateral-sensitivity against other antibiotics and exhibited a much slower growth rate due to the fitness cost caused by resistant mutations. These features indicate that Pept-ins show clear advantages over the conventional antibiotics and could have promising benefits during their 
therapeutic application. Furthermore, it seems more challenging for bacteria to become resistant towards Peptins which are less dependent on electrostatic attraction for uptake. In summary, the data presented here provides us more insights regarding the clinical development of Pept-ins, such as future Pept-ins should be selected for the ones which depend less on electrostatic attraction for uptake.

\section{Acknowledgements}

The Switch Laboratory was supported by grants from the European Research Council under the European Union's Horizon 2020 Framework Programme ERC Grant agreement 647458 (MANGO) to JS, the Flanders institute for biotechnology (VIB), the University of Leuven and its Industrieel Onderzoeksfonds, the Funds for Scientific Research Flanders (FWO), the FWO project AKUL/15/34 (Hercules Grant). Super resolution fluorescence and electron microscopy were performed at the Light Microscopy and Imaging Network (Limone) and the Electron Microscopy platform of VIB-KULeuven, respectively. FACS was carried out at the KU Leuven Flow Core. We thank professor John Elmerdahl Olsen (department of veterinary and animal sciences, university of Copenhagen, Denmark) for providing the potABCD or potFGHI knockout strains. We thank professor Diarmaid Hughes (department of Medical Biochemistry and Microbiology, university of Uppsala, Sweden) for providing the E. coli $\mathrm{CH} 184$ mutant strain.

\section{Author Contributions}

Conceptualization, G.W., L.K., L.K., J.S. and F.R.; Methodology, G.W., L.K., L.K., J.S. and F.R.; Validation, G.W.; Formal Analysis, G.W.; Investigation, G.W.; L.K., L.K. and M.D.V.; Writing - Original Draft, G.W.; Writing Review \& Editing, L.K., L.K., M.D.V., J.H. and B.H., J.S. and F.R.; Visualisation, G.W.; J.H. and B.H.; Resources, J.S. and F.R.; Supervision, L.K., L.K., J.S. and F.R.; Funding Acquisition, J.S. and F.R.

\section{Declaration of Interests}

F.R. and J.S. are listed as inventors of patents held by VIB, covering the peptides described in this manuscript. F.R. and J.S. are scientific founders of Aelin Therapeutics and members of its scientific advisory board. All remaining authors declare no competing financial interests.

\section{Figure titles and legends}

\section{Figure 1. Antibiotic resistance development of XL-1 Red cells.}

Daily MIC measurement of XL1-Red cells which were evolved under a daily treatment of vehicle or antibiotics at the concentration of 1/3 MIC (A-C) or 2/3 MIC (D-F). A. Daily ampicillin MIC measurement of XL1-Red cells treated by vehicle or ampicillin (at 1/3 MIC) for 27 days $(n=3)$. B. Daily P33 MIC measurement of XL1-Red cells treated by vehicle or P33 (at 1/3 MIC) for 27 days $(n=3)$. C. Daily P2 MIC measurement of XL1-Red cells treated by vehicle or P2 (at 1/3 MIC) for 27 days $(n=3)$. D. Daily ampicillin MIC measurement of XL1-Red cells treated by vehicle or ampicillin (at 2/3 MIC) for 16 days ( $n=3)$. E. Daily P33 MIC measurement of XL1-Red cells treated by vehicle or ampicillin (at 2/3 MIC) for 27 days $(n=3)$. F. Daily P2 MIC measurement of XL1-Red cells treated 
by vehicle or P2 (at 2/3 MIC) for 16 days ( $n=3$ ). G. OD600 values of strains from the end of the evolution experiment from 1/3 MIC treatment ( $n=$ at least 30) H. OD600 values of strains from the end of the evolution experiment from 2/3 MIC treatment ( $n=$ at least 30). Error bars represent SEM, two-tailed student $t$ test was performed for calculating statistical significance.

Figure 2. Collateral-sensitivity and cross-resistance profiles of evolved strains.

A MIC fold change above 1 indicates cross-resistance, whereas below 1 indicates collateral-sensitivity. The MIC fold change of tested antibiotics in vehicle-evolved (A), ampicillin-resistant (B), P33-resistant (C) and P2-resistant strains (D) compared to ancestors. (E) Negative charge determination at bacterial membrane by measuring FITC MFI after incubating bacteria with FITC-PLL $(1 \mu \mathrm{g} / \mathrm{mL})$ for $10 \mathrm{~min}$. Error bars represent SD, two-tailed student t test was performed for calculating statistical significance $(n=$ at least 6). (F) Representative histograms of FITCfluorescence distribution of ancestors and evolved strains. Untreated ancestors were included as a control.

\section{Figure 3. P2 uptake, IB formation and lipid composition of P2-resistant strains.}

Flow cytometry analysis of 40000 cells treated with FITC-P2 (A-C) for different time points from three independent experiments. A. The percentage of FITC-positive cells. B. FITC MFI of FITC-positive cell population. C. The percentage of FITC- and Draq7- positive cells. D. Wide-field structured illumination microscopy (SIM) images of bacteria treated with FITC-P2 for $2 \mathrm{~h}$ at $12.5 \mu \mathrm{g} / \mathrm{mL}$. Scale bar: $10 \mu \mathrm{m}$. E. FITC intensity in bacterial supernatant after the treatment with FITC-2DA-P2. F. SIM images of ancestors (left) and P2-resistant strains (middle) treated with P2 for $4 \mathrm{~h}$ at $6.25 \mu \mathrm{g} / \mathrm{mL}$, and P2-resistant strains treated with P2 for $4 \mathrm{~h}$ at $200 \mu \mathrm{g} / \mathrm{mL}$ (right). Amyloid-specific dye pFTAA was incubated with bacteria for $1.5 \mathrm{~h}$. G. SIM images of ancestors (left) and P2-resistant strains (right) treated with P33 for $4 \mathrm{~h}$ at $6.5 \mu \mathrm{g} / \mathrm{mL}$. The percentage of main lipid classes $(\mathbf{H})$, negatively charged lipid class (I) and unsaturated lipid class (J) from ancestors, vehicle-derived cells and P2resistant cells. Error bars represent SEM for A-C $(n=9)$, SD for E $(n=18)$ and SD for H-J $(n=5)$. Two-tailed student $t$ test was performed for calculating statistical significance.

\section{Figure 4. Gene ontology of genes which showed significantly changed expression in P2-resistant strains.}

A. The number of genes in biological pathways enriched from differently expressed genes in P2-resistant strains compared to ancestors. A Bonferroni step-down $\mathrm{P}$ value $<0.05$ is considered as significant. (Except L-ascorbic acid metabolic process and resistance to acid stress which showed a P value $>0.05)$. B. The fold change of gene expression for genes which are involved in bacterial membrane charge modification.

\section{Figure 5. Whole genome sequencing of evolved strains.}

The number of mutations (A) and the number of mutated genes (B) accumulated in evolved strains from the end of evolution experiment, blue bars: treated at 1/3 MIC concentration for 27 days, red bars: treated at 2/3 MIC concentration for 16 days (vehicle, ampicillin and P2) or 27 days (P33). Error bars represent SD. For 1/3 MIC treatment, $\mathrm{n}=1$ for vehicle, 1 for AMP, 3 for P33 and 4 for P2. For 2/3 MIC treatment, $\mathrm{n}=2$ for vehicle, 2 for AMP, 3 for P33 and 8 for P2. C. The frequency of each coding mutation occurred across different types of 
treatment at the end of the evolution experiment. The colour dark blue to yellow in the heat map indicating an increased frequency. D. The number of genes with coding mutation accumulated at day 13, day 18, day 21 and day 27 for strains evolved from vehicle (blue) or P2 (red) treatment at the concentration of 1/3 MIC. Error bars represent SEM $(n=4,3,3$ and 1 for vehicle treatment at day 13, 18, 21 and 27, respectively. $n=4,3,3$ and 4 for P2 treatment at day 13, 18, 21 and 27, respectively. E. The number of strains which exhibited the same mutated gene (with coding mutation) from $\mathbf{D}$ across the 12 colonies for vehicle and P2 treatment. The colour white to blue in the heat map indicating an increased number of genes. F. Number of genes which were fixed at either day 13, day 18 or day 21 , occurred at day 27 as well as these unfixed spontaneous mutations for vehicle- and P2-evolved strains. The gene number of biological pathways enriched from genes with coding mutation which are fixed at day 13 or at day 27 for vehicle $(\mathbf{G})$ and P2 (H) evolved strains. Two-tailed student t test was performed for calculating statistical significance.

Figure 6. P2 uptake, IB formation and negative charge at membrane of clinical isolates.

A. SIM images of E. cloacae 48, 51, 77 and $K$. pneumoniae upon FITC-P2 treatment at $25 \mu \mathrm{g} / \mathrm{mL}$ for 2 h. Amyloidspecific dye HS169 was incubated with bacteria for $10 \mathrm{~min}$ before image acquisition. B. Fluorescent intensity quantification of FITC for images shown in A. C. Fluorescent intensity quantification of HS169 for images shown in A. D. SIM images of E. cloacae 48, 51, 77 and $K$. pneumoniae upon FITC-PLL treatment at $1 \mu \mathrm{g} / \mathrm{mL}$ for $10 \mathrm{~min}$ at room temperature in the dark. E. Fluorescent intensity quantification of FITC for images shown in D. Scale bar: $10 \mu \mathrm{m}$. Error bars represent SD $(\mathrm{n}=3)$. Two-tailed student $\mathrm{t}$ test was performed for calculating statistical significance.

Tables

Table 1. Pept-in MIC in XL1-Red cells

\begin{tabular}{|l|l|l|}
\hline Peptide & Sequence* & MIC $(\mu \mathrm{g} / \mathrm{mL})$ \\
\hline P2 & RGLGLALVRRPRGLGLALVRR & 6,5 \\
\hline P33 & RLGIAVALRRPRLGIAVALRR & 3,25 \\
\hline P5 & RALLTTLLRRPRALLTTLLRR & 3,25 \\
\hline
\end{tabular}

* Red amino acids are Pept-in APR regions

\section{STAR $\star$ METHODS}

Detailed methods are provided in the online version of this paper and include the following:

- KEY RESOURCES TABLE

- RESOURCE AVAILABILITY

- Lead Contact

○ Materials Availability

- Data and Code Availability

- EXPERIMENTAL MODEL AND SUBJECT DETAILS

- METHOD DETAILS 
KEY RESOURCES TABLE

\begin{tabular}{|c|c|c|}
\hline REAGENT or RESOURCE & SOURCE & IDENTIFIER \\
\hline \multicolumn{3}{|l|}{ Bacterial and Virus Strains } \\
\hline E. coli XL1 Red & Agilent & 200129 \\
\hline E. coli KEIO knockouts & Dharmacon & OEC4988 \\
\hline $\begin{array}{l}\text { E. coli } \triangle \text { pot } A B C D \text { and } \\
\triangle \text { potFGHI }\end{array}$ & (Guerra et al., 2018) & $\mathrm{N} / \mathrm{A}$ \\
\hline E. coli $\mathrm{CH} 184$ & $\begin{array}{l}\text { (Sergei Proshkin, Rachid Rahmouni, } \\
\text { Alexander Mironov, 2010) }\end{array}$ & N/A \\
\hline $\begin{array}{l}\text { Clinical isolates of } E \text {. } \\
\text { cloacae and } K \text {. pneumoniae }\end{array}$ & UZ leuven, Belgium & $\mathrm{N} / \mathrm{A}$ \\
\hline \multicolumn{3}{|c|}{ Chemicals, Peptides, and Recombinant Proteins } \\
\hline P2, P33 & GenScript & Order \#: U4291EB210 \\
\hline Ampicillin & Duchefa biochemie & Cat \#: A0104.0005 \\
\hline Chloramphenicol & Duchefa biochemie & Cat \#: C0113.0025 \\
\hline Kanamycin & Duchefa biochemie & Cat \#: K0126.0005 \\
\hline Tetracycline & Duchefa biochemie & Cat \#: T0150.0025 \\
\hline Spectinomycin & Duchefa biochemie & Cat \#: S0188.0005 \\
\hline Rifamycin & LabConsult & Cat \#: SERV.3451401 \\
\hline Ciprofloxacin & Argos/Thermo & Cat \#: 449620050 \\
\hline Cerulenin & Enzolifesciences & Cat \#: 5291-500MG \\
\hline Polymyxin B & Sigma & Cat \#: 5291-500MG \\
\hline Polymyxin E & Fisher & Cat \#: 455392500 \\
\hline Draq7 & BioStatus & Cat \#: DR71000 \\
\hline FITC-PLL & Sigma & Cat \#: P3543-10MG \\
\hline \multicolumn{3}{|l|}{ Critical Commercial Assays } \\
\hline MagAttract HMW DNA Kit & Qiagen & Cat \#: 67563 \\
\hline \multicolumn{3}{|l|}{ Deposited Data } \\
\hline $\begin{array}{l}\text { Raw lipidomics data, the } \\
\text { data set is related to figure } \\
\text { 3G-3I. }\end{array}$ & This study & $\begin{array}{l}\text { Mendeley data, } \\
\text { DOI: } 10.17632 / 9 \mathrm{kpvymt} 83 \mathrm{c} .1\end{array}$ \\
\hline $\begin{array}{l}\text { Raw microarray data, the } \\
\text { data set is related to figure } 4 \text {. }\end{array}$ & This study & $\begin{array}{l}\text { Mendeley data, } \\
\text { DOI: } 10.17632 / \text { sxy } 5 x k n p m 5.1\end{array}$ \\
\hline $\begin{array}{l}\text { Raw NGS data, the data set } \\
\text { is related to figure } 3 G-3 I \text {. }\end{array}$ & This study & $\begin{array}{l}\text { Mendeley data, } \\
\text { DOI: } 10.17632 / 5 \mathrm{px} 5 \mathrm{kdd} 29 \mathrm{x} .1\end{array}$ \\
\hline \multicolumn{3}{|l|}{ Software and Algorithms } \\
\hline GraphPad Prism 9.0 & GraphPad Software, USA & https://www.graphpad.com \\
\hline RStudio v 1.2.5001 & RStudio, USA & https://rstudio.com \\
\hline FlowJo ${ }^{\mathrm{TM}}$ Software 10.7.1 & Ashland, USA & https://www.flowjo.com \\
\hline FIJI 2.0.0-rc-68/1.52f & (Schindelin et al., 2012) & https://fiji.sc \\
\hline MicrobeJ 5.13I & (Ducret, Quardokus and Brun, 2016) & https://www.microbej.com \\
\hline DAVID v6.7 & (Dennis et al., 2003) & https://david.ncifcrf.gov/tools.jsp \\
\hline Cluego v2.5.4 & (Bindea et al., 2009) & $\begin{array}{l}\text { http://apps.cytoscape.org/apps/ } \\
\text { cluego }\end{array}$ \\
\hline Cytoscape 3.7 .2 & (Otasek et al., 2019) & https://cytoscape.org \\
\hline \multicolumn{3}{|l|}{ Others } \\
\hline Illumina sequencing & MicrobesNG, UK & QT02616 and QT3077 \\
\hline Microarray & OakLabs GmbH, Germany & Quote \#: 22016941 \\
\hline Lipidomics analysis & Lipotype, Germany & QS-20-245 \\
\hline
\end{tabular}




\section{RESOURCE AVAILABILITY}

\section{Lead Contact}

Further information and requests for resources and reagents should be directed to and will be fulfilled by the lead Contact, Joost Schymkowitz (joost.schymkowitz@switch.vib-kuleuven.be).

\section{Materials Availability}

All Pept-in resistant strains generated in this study are available from the Lead Contact with a completed Material Transfer Agreement.

\section{Data and Code Availability}

The original microarray data generated during this study have been deposited to [DOI: 10.17632/sxy5xknpm5.1 / https://data.mendeley.com/datasets/sxy5xknpm5/1].

The original NGS data generated during this study have been deposited to [DOI: 10.17632/5px5kdd29x.1/ https://data.mendeley.com/datasets/5px5kdd29x/1].

The original lipidomics data generated during this study have been deposited to [DOI: 10.17632/9kpvymt83c.1 / https://data.mendeley.com/datasets/9kpvymt83c/1].

\section{EXPERIMENTAL MODEL AND SUBJECT DETAILS}

E. coli XL1 Red, E. coli KEIO knockout strains, clinical isolates of E. cloacae and K. pneumoniae were cultured as described in the Method details.

\section{METHOD DETAILS}

\section{Peptide preparation}

Peptides were either synthesised in the Switch laboratory using standard solid-phase peptide synthesis (JPT, Berlin, Germany) or purchased from GenScript (Leiden, The Netherlands). Peptides with $\geq 90 \%$ purity were used in the downstream experiments. The lyophilised peptides were dissolved at $1-5 \mathrm{mg} / \mathrm{ml}$ in $6 \mathrm{M}$ Urea and sonicated for $5 \mathrm{~min}$ in a water sonication bath to make sure they were completely dissolved. The peptide stock was further diluted to desired experimental concentrations.

\section{MIC determination}

The peptide MIC was determined via the broth microdilution assay according to the EUCAST guideline, using 96well polystyrene flat bottom microtiter plates (BD Biosciences). Briefly, a single colony was inoculated in $5 \mathrm{~mL}$ Mueller-Hinton $(\mathrm{MH})$ medium and incubated, while shaking at $37^{\circ} \mathrm{C}$, to the end-exponential growth phase. The bacterial culture was subsequently diluted to $0.005 \mathrm{McFarland}(\mathrm{McF})\left(\sim 1.5 \times 10^{6} \mathrm{CFU} / \mathrm{mL}\right)$ with fresh $\mathrm{MH}$ medium. Two-fold serial peptide-dilutions were prepared in $50 \mu \mathrm{L} \mathrm{MH}$ medium resulting in a concentration range of 0.75 to $100 \mu \mathrm{g} / \mathrm{mL}$ (at least three wells for each concentration). Afterwards, $50 \mu \mathrm{L}$ of the freshly diluted bacterial suspension (0.005 McF) was mixed with different peptide concentrations in the 96-well plate, performed in 
triplicates. The plate was ultimately incubated at $37^{\circ} \mathrm{C}$ overnight without shaking for 17 hours. The MIC was determined as the lowest peptide-concentration without visible bacterial growth.

\section{Adaptive laboratory evolution experiment}

The adaptive laboratory evolution experiment was performed to test the antibiotic resistance development of E.coli XL1-Red cells (Agilent Technologies) as described previously (Suzuki, Horinouchi and Furusawa, 2014; Khodaparast et al., 2018). A single XL1-Red colony was inoculated in $5 \mathrm{~mL} \mathrm{MH}$ medium and grown for 20 hours. The bacterial culture was subsequently diluted to $0.005 \mathrm{McF}$ and used as the ancestor cells for the evolution experiment. Three independent cultures, treated daily with the corresponding antibiotic (ampicillin, P2 and P33) or vehicle (PBS), were propagated in parallel in a 96-well polystyrene flat bottom microtiter plate. The plates were sealed with breathable membranes (Breathe-Easy) and incubated at $37^{\circ} \mathrm{C}$ for 20 hours without shaking. At a daily transfer, MIC of the antibiotic, which was used for bacteria treatment, was determined to assess whether the treatment caused an MIC increase. For vehicle treated bacteria, the MIC for ampicillin, P2 and P33 was determined daily as well. Treated bacteria was further diluted to $0.005 \mathrm{McF}$ to continue the evolution experiment and the concentration of antibiotic treatment for the next day was adjusted according to the newly obtained MIC value. Cultures were either evolved for 27 days under $1 / 3$ MIC treatment or 16 days under 2/3 MIC treatment. Daily bacteria samples were stored in $80 \%$ glycerol stock at $-80^{\circ} \mathrm{C}$ until further use.

\section{Grow rate determination}

Bacterial glycerol stock was streaked out on a $\mathrm{MH}$ plate and incubated for 40 hours at $37^{\circ} \mathrm{C}$. A single colony isolated from the $\mathrm{MH}$ plates was inoculated in $5 \mathrm{~mL} \mathrm{MH}$ medium and incubated for 17 hours while shaking at $37^{\circ} \mathrm{C}$. Bacterial culture was diluted with fresh $\mathrm{MH}$ medium to $0.005 \mathrm{McF}$ and $200 \mu \mathrm{L}$ of which were added into a 96 well plate. The plate was sealed with breathable membrane and loaded into the plate reader FLUOstar Omega (BMG LABTECH) at $37^{\circ} \mathrm{C}$. The optical density at $600 \mathrm{~nm}$ (OD600) was monitored at 10 min intervals for $20 \mathrm{~h}$.

\section{Collateral sensitivity and cross-resistance analysis}

To detect the collateral sensitivity and cross-resistance profile of evolved strains compared to the ancestors, the MIC of 14 antibiotics with 6 different modes of action were determined. The tested antibiotics include ampicillin (Duchefa biochemie), chloramphenicol (Duchefa biochemie), kanamycin (Duchefa biochemie), tetracycline (Duchefa biochemie), spectinomycin (Duchefa biochemie), rifamycin (LabConsult), ciprofloxacin (Argos/Thermo), cerulenin (Enzolifesciences), polymyxin B (Sigma), polymyxin E (Fisher) and pexiganan (Synthesised in the Switch laboratory as described above). Antibiotics were prepared following the manufacturer's instructions and the MIC was determined as described above.

\section{Flow cytometry analysis of peptide treated bacteria}

Flow cytometry is used to determine peptide accumulation inside bacteria and its correlation with bacterial death. Briefly, end-exponential growth phase bacteria were washed twice with filtered PBS (7 $000 \mathrm{rpm}, 4 \mathrm{~min}$ ) 
and diluted to $0.5 \mathrm{McF}\left(1.5 \times 10^{8} \mathrm{CFU} \mathrm{mL}{ }^{-1}\right)$ with PBS (pH 7.4). $1 \mathrm{~mL}$ bacteria suspension was treated with FITClabelled peptide at the described concentrations and incubated at $37^{\circ} \mathrm{C}$ without shaking for the following time points: $15 \mathrm{~min}, 2 \mathrm{~h}, 4 \mathrm{~h}$ and $6 \mathrm{~h}$. Treated bacteria were washed three times (7 $000 \mathrm{rpm}, 4 \mathrm{~min}$ ) with PBS (pH 7.4) and resuspended in $500 \mu \mathrm{L}$ PBS. $1 \mu \mathrm{L}$ of Draq7 (Biostatus) was added and incubated for $10 \mathrm{~min}$ at room temperature in the dark.

FITC labelled poly-L-lysine (FITC-PLL, Sigma) was used to determine the negative charge at bacterial membrane based on previously described protocols (Kintses et al., 2019). Briefly, FITC-PLL was dissolved with PBS at 1 $\mathrm{mg} / \mathrm{mL}$. End-exponential growth phase bacteria were washed twice with filtered PBS (pH 7.4) (7 $000 \mathrm{rpm}, 4 \mathrm{~min}$ ) and diluted to $0.5 \mathrm{McF}\left(1.5 \times 10^{8} \mathrm{CFU} \mathrm{mL} \mathrm{mL}^{-1}\right)$ with PBS. $1 \mathrm{~mL}$ bacteria suspension was treated with FITC-PLL at 1 $\mu \mathrm{g} / \mathrm{mL}$ for $10 \mathrm{~min}$ at room temperature in the dark. Treated bacteria were washed three times (7 $000 \mathrm{rpm}, 4$ min) with PBS and resuspended in $500 \mu \mathrm{LBS}$ (pH 7.4). All samples were acquired on a Gallios Flow Cytometry (Beckman Coulter) and data were analysed with Flowjo software version 10.6. FITC: excitation $490 \mathrm{~nm}$ and emission 525 nm, Draq7: excitation $633 \mathrm{~nm}$ and emission $697 \mathrm{~nm}$.

\section{Super-resolution microscopy of peptide treated bacteria}

Peptide treated bacteria were stained with amyloid-specific dye pFTAA (0.5 $\mu \mathrm{M})$ or HS169 (0.5 $\mu \mathrm{M})$ and visualised with super-resolution microscopy (SIM) to confirm the presence of inclusion body formation in bacteria. Briefly end-exponential growth phase bacteria were washed twice with filtered PBS (7 $000 \mathrm{rpm}, 4 \mathrm{~min}$ ) and diluted to $0.5 \mathrm{McF}\left(1.5 \times 10^{8} \mathrm{CFU} \mathrm{mL} \mathrm{mL}^{-1}\right)$ with PBS. $1 \mathrm{~mL}$ diluted bacteria suspension was treated with peptide at the described concentration for $2 \mathrm{~h}$ and followed by another $1.5 \mathrm{~h}$ treatment of $10 \mu \mathrm{L} \mathrm{pFTAA}$ at $37^{\circ} \mathrm{C}$ without shaking. Propidium iodide (PI) or HS169 was added and incubated for $10 \mathrm{~min}$ at room temperature in the dark. Bacteria samples were visualised by SIM and acquired images were analysed on the image processing software FIJI (Schindelin et al., 2012). Fluorescent intensity quantification of acquired images was performed using microbeJ (Ducret, Quardokus and Brun, 2016). pFTAA: excitation 450 nm and emission 520/20 nm, PI: excitation $536 \mathrm{~nm}$ and emission 617/20 nm. HS169: excitation $535 \mathrm{~nm}$ and emission 665/20 nm.

\section{Lipidomic analyses}

Five independent colonies of ancestors, vehicle-treated and P2-resistant colonies from the end of 1/3 MIC treatment were isolated from MH agar plates. They were further inoculated into $200 \mathrm{~mL} \mathrm{MH}$ medium and grown in the absence of antibiotics for $17 \mathrm{~h}$ at $37^{\circ} \mathrm{C}$ with shaking. For lipidomic analyses, bacterial culture was collected by centrifugation (7 $000 \mathrm{rpm}, 4 \mathrm{~min}$ ) and washed twice with Milli-Q water. The pellet was resuspended in Milli$\mathrm{Q}$ water and snap-frozen in liquid nitrogen. Bacterial sample was resuspended in $20 \mathrm{OD}_{600} \mathrm{units} / \mathrm{mL}$. Cells were lysed with zirconia beads using cell disruptor for 10 mins on ice. The lipids were measured by Lipotype Shotgun Lipidomics service (Lipotype) as previously described (Gerl et al., 2012). Data was further analysed with Graphpad.

\section{Microarray analysis and bioinformatic analyses}


Four independent strains of ancestors and P2-resistant cells were selected from the overnight culture prepared for lipidomic analysis. Overnight culture was diluted with fresh $\mathrm{MH}$ medium to $0.5 \mathrm{McF}, 20 \mathrm{~mL}$ of which was either treated with vehicle or P2 $(3.25 \mu \mathrm{g} / \mathrm{mL})$ for $4 \mathrm{~h}$ at $37{ }^{\circ} \mathrm{C}$ with shaking. Treated bacterial culture was collected by centrifugation (7 $000 \mathrm{rpm}, 4 \mathrm{~min}$ ) and the pellet was stored at $-80^{\circ} \mathrm{C}$ before shipping. RNA isolation and transcriptomic analysis were carried out by Oaklabs (Berlin, Germany). Briefly, fluorescent complementary RNA (cRNA) was generated from high-quality total RNA by using low Input QuickAmp Labeling Kit (Agilent Technologies). cDNA synthesis was performed by using WT primer. Labelled cDNA was hybridised on $8 \times 60 \mathrm{~K}$ glass slide using agilent gene expression hybridisation kit (Agilent Technologies). Fluorescence signals on microarrays are detected by the SureScan Microarray Scanner (Agilent Technologies), generating a 20 bit TIFF file. This file was read and processed using Agilent's Feature Extraction software version 11. The gene ontology analysis of genes which exhibited at least 2-fold change $(p<0.05)$ was performed using ClueGO plug-in of Cytoscape (Bindea et al., 2009; Otasek et al., 2019). Biological pathways with $p \leq 0.05$ were selected and ranked based on the $p$ value.

\section{Next generation sequencing and bioinformatic analyses}

To identify mutations which contribute to P2 resistance, ancestors and evolved strains were sequenced by MicrobesNG (Birmingham, UK) on Illumina sequencing platform. A single colony isolated from $\mathrm{MH}$ plates was grown in $50 \mathrm{~mL} \mathrm{MH}$ medium in the absence of antibiotics until the end-exponential growth phase. The genomic DNA of collected bacteria was extracted using MagAttract HMW DNA Kit (Qiagen). Genomic DNA samples were sent to MicrobesNG for downstream library preparation, sequencing and bioinformatic analyses (trimming of raw data, alignment to the reference genome and variant calling). For genome annotation as well as variant calling, genome sequence (AP012030) downloaded from NCBI for E. coli strain DH1 was used as reference. Mutations occurred in ancestor strains were removed from all samples before further analysis. Gene ontology analysis was performed using David data base tools (Dennis et al., 2003). Biological pathways with $p \leq 0.05$ were selected and ranked based on the $p$ value.

\section{MIC determination of knock out strains}

To assess the effect of genes of interest on causing P2 resistance, the MIC of P2 against 120 single-gene knockout strains purchased from Dharmacon E. coli Keio Knockout collection was determined. The background strain $\mathrm{E}$. coli K-12 BW25113 was included as control.

\section{QUANTIFICATION AND STASTICAL ANALYSIS}

All experiments were performed in minimum three replicates. For statistical evaluation of the determined averages and standard deviations of the mean, data were analysed for significant differences using the statistical tests indicated in the figure legends or text, and included corrections for multiple testing when required. Statistical calculations were performed using Prism or R Studio (RStudio Team, 2020), unless otherwise indicated. Asterisks indicating the level of the $P$ value centred over the error bar mean: ${ }^{*} P<0.05, * * P<0.01, * * * P<0.001$, and $* * * * P<0.0001$. 


\section{Supplemental figure titles and legends}

Figure S1. IB formation of $E$. coli wild-type (WT) and CH184 mutant strain upon Pept-in treatment.

A. SIM images of E. coli WT and CH184 mutant strain upon P2 treatment at $12.5 \mu \mathrm{g} / \mathrm{mL}$ for $2 \mathrm{~h}$. Amyloid-specific dye pFTAA was incubated with bacteria for $1.5 \mathrm{~h}$. B. Fluorescent intensity quantification of pFTAA of images shown in Fig A. C. SIM images of E. coli WT and CH184 mutant strain upon P33 treatment at $6.5 \mu \mathrm{g} / \mathrm{mL}$ for 2 h. Amyloid-specific dye pFTAA was incubated with bacteria for $1.5 \mathrm{~h}$. B. Fluorescent intensity quantification of pFTAA of images shown in Fig C. Scale bar: $10 \mu \mathrm{m}$. Error bars represent SD $(n=3)$, Two-tailed student $t$ test was performed for calculating statistical significance.

\section{Supplemental tables}

Table S1. P2 and P33 MIC in wild-type and CH184 mutant strain, related to Figure S1.

Table S2. Antibiotics which are used to determine the collateral-sensitivity and cross-resistance profile of evolved strains, related to Figure 2.

Table S3. Downregulated transporters, related to Figure 4.

Table S4. P2 MIC of knock out strains, related to Figure 5.

Table S5. P2 MIC in different clinical isolates, related to Figure 6.

\section{References}

Åslund, A., Sigurdson, C. J., Klingstedt, T., Grathwohl, S., Bolmont, T., Dickstein, D. L., Glimsdal, E., Prokop, S., Lindgren, M., Konradsson, P., Holtzman, D. M., Hof, P. R., Heppner, F. L., Gandy, S., Jucker, M., Aguzzi, A., Hammarström, P. and Nilsson, K. P. R. (2009) 'Novel pentameric thiophene derivatives for in vitro and in vivo optical imaging of a plethora of protein aggregates in cerebral amyloidoses', ACS Chemical Biology, 4(8), pp. 673-684. doi: 10.1021/cb900112v.

Baba, T., Ara, T., Hasegawa, M., Takai, Y., Okumura, Y., Baba, M., Datsenko, K. A., Tomita, M., Wanner, B. L. and Mori, H. (2006) 'Construction of Escherichia coli K-12 in-frame, single-gene knockout mutants: The Keio collection', Molecular Systems Biology, 2. doi: 10.1038/msb4100050.

Barrick, J. E., Yu, D. S., Yoon, S. H., Jeong, H., Oh, T. K., Schneider, D., Lenski, R. E. and Kim, J. F. (2009) ‘Genome evolution and adaptation in a long-term experiment with Escherichia coli', Nature, 461(7268), pp. $1243-1247$. doi: $10.1038 /$ nature08480.

Bednarska, N. G., van Eldere, J., Gallardo, R., Ganesan, A., Ramakers, M., Vogel, I., Baatsen, P., Staes, A., Goethals, M., Hammarström, P., Nilsson, K. P. R., Gevaert, K., Schymkowitz, J. and Rousseau, F. (2016a) 'Protein aggregation as an antibiotic design strategy', Molecular Microbiology, 99(5), pp. 849-865. doi: 10.1111/mmi.13269. 
Bednarska, N. G., van Eldere, J., Gallardo, R., Ganesan, A., Ramakers, M., Vogel, I., Baatsen, P., Staes, A., Goethals, M., Hammarström, P., Nilsson, K. P. R., Gevaert, K., Schymkowitz, J. and Rousseau, F. (2016b) 'Protein aggregation as an antibiotic design strategy', Molecular Microbiology, 99(5), pp. 849-865. doi: 10.1111/mmi.13269.

Betti, C., Vanhoutte, I., Coutuer, S., De Rycke, R. M., Mishev, K., Vuylsteke, M., Aesaert, S., Rombaut, D., Gallardo, R., De Smet, F., Xu, J., Van Lijsebettens, M., Van Breusegem, F., Inzé, D., Rousseau, F., Schymkowitz, J. and Russinova, E. (2016) 'Sequence-specific protein aggregation generates defined protein knockdowns in plants', Plant Physiology, 171(June), p. pp.00335.2016. doi: 10.1104/pp.16.00335.

Bindea, G., Mlecnik, B., Hackl, H., Charoentong, P., Tosolini, M., Kirilovsky, A., Fridman, W. H., Pagès, F., Trajanoski, Z. and Galon, J. (2009) 'ClueGO: A Cytoscape plug-in to decipher functionally grouped gene ontology and pathway annotation networks', Bioinformatics, 25(8), pp. 1091-1093. doi: 10.1093/bioinformatics/btp101.

Blair, J. M. A., Webber, M. A., Baylay, A. J., Ogbolu, D. O. and Piddock, L. J. V. (2015) 'Molecular mechanisms of antibiotic resistance', Nature Reviews Microbiology, 13(1), pp. 42-51. doi: 10.1038/nrmicro3380.

Butler, M. S. and Paterson, D. L. (2020) 'Antibiotics in the clinical pipeline in October 2019', Journal of Antibiotics. Springer US, 73(6), pp. 329-364. doi: 10.1038/s41429-020-0291-8.

Calvo-Rodriguez, M., Hou, S. S., Snyder, A. C., Dujardin, S., Shirani, H., Nilsson, K. P. R. and Bacskai, B. J. (2019) 'In vivo detection of tau fibrils and amyloid $\beta$ aggregates with luminescent conjugated oligothiophenes and multiphoton microscopy', Acta neuropathologica communications, 7(1), p. 171. doi: 10.1186/s40478-0190832-1.

Cardoso, M. H., Meneguetti, B. T., Costa, B. O., Buccini, D. F., Oshiro, K. G. N., Preza, S. L. E., Carvalho, C. M. E., Migliolo, L. and Franco, O. L. (2019) 'Non-lytic antibacterial peptides that translocate through bacterial membranes to act on intracellular targets', International Journal of Molecular Sciences, 20(19). doi: 10.3390/ijms20194877.

Culp, E. J., Waglechner, N., Wang, W., Fiebig-Comyn, A. A., Hsu, Y. P., Koteva, K., Sychantha, D., Coombes, B. K., Van Nieuwenhze, M. S., Brun, Y. V. and Wright, G. D. (2020) 'Evolution-guided discovery of antibiotics that inhibit peptidoglycan remodelling', Nature, 578(7796), pp. 582-587. doi: 10.1038/s41586-020-1990-9.

Czaplewski, L., Bax, R., Clokie, M., Dawson, M., Fairhead, H., Fischetti, V. A., Foster, S., Gilmore, B. F., Hancock, R. E. W., Harper, D., Henderson, I. R., Hilpert, K., Jones, B. V., Kadioglu, A., Knowles, D., Ólafsdóttir, S., Payne, D., Projan, S., Shaunak, S., Silverman, J., Thomas, C. M., Trust, T. J., Warn, P. and Rex, J. H. (2016) 'Alternatives to antibiotics-a pipeline portfolio review', The Lancet Infectious Diseases, 16(2), pp. 239-251. doi: 10.1016/S1473-3099(15)00466-1.

David, D. C., Ollikainen, N., Trinidad, J. C., Cary, M. P., Burlingame, A. L. and Kenyon, C. (2010) 'Widespread protein aggregation as an inherent part of aging in C. elegans', PLoS Biology, 8(8), pp. 47-48. doi: 10.1371/journal.pbio.1000450.

Dennis, G., Sherman, B. T., Hosack, D. A., Yang, J., Gao, W., Lane, H. C. and Lempicki, R. A. (2003) 'DAVID: Database for Annotation, Visualization, and Integrated Discovery.', Genome biology, 4(5), p. 2003. doi: 10.1186/gb-2003-4-9-r60. 
Ducret, A., Quardokus, E. M. and Brun, Y. V. (2016) 'MicrobeJ, a tool for high throughput bacterial cell detection and quantitative analysis', Nature Microbiology. Nature Publishing Group, 1(7), pp. 1-7. doi: 10.1038/nmicrobiol.2016.77.

Eisenberg, D. and Jucker, M. (2012) 'The amyloid state of proteins in human diseases', Cell, 148(6), pp. 11881203. doi: 10.1016/j.cell.2012.02.022.

Epand, R. F., Maloy, W. L., Ramamoorthy, A. and Epand, R. M. (2010) 'Probing the "charge cluster mechanism" in amphipathic helical cationic antimicrobial peptides', Biochemistry, 49(19), pp. 4076-4084. doi: 10.1021/bi100378m.

Gallardo, R., Ramakers, M., De Smet, F., Claes, F., Khodaparast, Ladan, Khodaparast, Laleh, Couceiro, J. R., Langenberg, T., Siemons, M., Nyström, S., Young, L. J., Laine, R. F., Young, L., Radaelli, E., Benilova, I., Kumar, M., Staes, A., Desager, M., Beerens, M., Vandervoort, P., Luttun, A., Gevaert, K., Bormans, G., Dewerchin, M., Van Eldere, J., Carmeliet, P., Velde, G. Vande, Verfaillie, C., Kaminski, C. F., De Strooper, B., Hammarström, P., Nilsson, K. P. R., Serpell, L., Schymkowitz, J. and Rousseau, F. (2016) ‘De novo design of a biologically active amyloid', Science, 354(6313). doi: 10.1126/science.aah4949.

Ganesan, A., Siekierska, A. and Schymkowitz, J. (2016) 'Structural hot spots for the solubility of globular proteins Protein abundance correlates with aggregation prone regions Protein sequences possess cryptic APRs'.

Gerl, M. J., Sampaio, J. L., Urban, S., Kalvodova, L., Verbavatz, J. M., Binnington, B., Lindemann, D., Lingwood, C. A., Shevchenko, A., Schroeder, C. and Simons, K. (2012) 'Quantitative analysis of the lipidomes of the influenza virus envelope and MDCK cell apical membrane', Journal of Cell Biology, 196(2), pp. 213-221. doi: 10.1083/jcb.201108175.

Greener, A., Callahan, M. and Jerpseth, B. (1997) 'An Efficient Random Mutagenesis Technique Using an E. coli Mutator Strain', Applied Biochemistry and Biotechnology - Part B Molecular Biotechnology, 7(2), pp. 189-195. doi: 10.1007/BF02761755.

Guerra, P. R., Herrero-Fresno, A., Ladero, V., Redruello, B., Dos Santos, T. P., Spiegelhauer, M. R., Jelsbak, L. and Olsen, J. E. (2018) 'Putrescine biosynthesis and export genes are essential for normal growth of avian pathogenic Escherichia coli', BMC Microbiology, 18(1), pp. 1-12. doi: 10.1186/s12866-018-1355-9. Jahn, L. J., Munck, C., Ellabaan, M. M. H. and Sommer, M. O. A. (2017) 'Adaptive laboratory evolution of antibiotic resistance using different selection regimes lead to similar phenotypes and genotypes', Frontiers in Microbiology, 8(MAY), pp. 1-14. doi: 10.3389/fmicb.2017.00816.

Khodaparast, Ladan, Khodaparast, Laleh, Gallardo, R., Louros, N. N., Michiels, E., Ramakrishnan, R., Ramakers, M., Claes, F., Young, L., Shahrooei, M., Wilkinson, H., Desager, M., Mengistu Tadesse, W., Nilsson, K. P. R., Hammarström, P., Aertsen, A., Carpentier, S., Van Eldere, J., Rousseau, F. and Schymkowitz, J. (2018) 'Aggregating sequences that occur in many proteins constitute weak spots of bacterial proteostasis', Nature Communications, 9(1). doi: 10.1038/s41467-018-03131-0.

Khondker, A., Dhaliwal, A. K., Saem, S., Mahmood, A., Fradin, C., Moran-Mirabal, J. and Rheinstädter, M. C. (2019) 'Membrane charge and lipid packing determine polymyxin-induced membrane damage', Communications Biology, 2(1), pp. 1-11. doi: 10.1038/s42003-019-0297-6. 
Kintses, B., Méhi, O., Ari, E., Számel, M., Györkei, Á., Jangir, P. K., Nagy, I., Pál, F., Fekete, G., Tengölics, R., Nyerges, Á., Likó, I., Bálint, A., Molnár, T., Bálint, B., Vásárhelyi, B. M., Bustamante, M., Papp, B. and Pál, C. (2019) 'Phylogenetic barriers to horizontal transfer of antimicrobial peptide resistance genes in the human gut microbiota', Nature Microbiology. Springer US, 4(3), pp. 447-458. doi: 10.1038/s41564-018-0313-5.

Kryazhimskiy, S. and Plotkin, J. B. (2008) 'The population genetics of dN/dS', PLoS Genetics, 4(12). doi: 10.1371/journal.pgen.1000304.

Lázár, V., Martins, A., Spohn, R., Daruka, L., Grézal, G., Fekete, G., Számel, M., Jangir, P. K., Kintses, B., Csörgo, B., Nyerges, Á., Györkei, Á., Kincses, A., Dér, A., Walter, F. R., Deli, M. A., Urbán, E., Hegedus, Z., Olajos, G., Méhi, O., Bálint, B., Nagy, I., Martinek, T. A., Papp, B. and Pál, C. (2018) 'Antibiotic-resistant bacteria show widespread collateral sensitivity to antimicrobial peptides', Nature Microbiology, 3(6), pp. 718-731. doi: 10.1038/s41564-018-0164-0.

Lee, H. H., Molla, M. N., Cantor, C. R. and Collins, J. J. (2010) 'Bacterial charity work leads to population-wide resistance', Nature, 467(7311), pp. 82-85. doi: 10.1038/nature09354.

Li, Y. X., Zhong, Z., Zhang, W. P. and Qian, P. Y. (2018) ‘Discovery of cationic nonribosomal peptides as Gramnegative antibiotics through global genome mining', Nature Communications, 9(1), pp. 2-10. doi: 10.1038/s41467-018-05781-6.

Long, H., Miller, S. F., Strauss, C., Zhao, C., Cheng, L., Ye, Z., Griffin, K., Te, R., Lee, H., Chen, C.-C. and Lynch, M. (2016) 'Antibiotic treatment enhances the genome-wide mutation rate of target cells', Proceedings of the National Academy of Sciences, 113(18), pp. E2498-E2505. doi: 10.1073/pnas.1601208113.

Manuscript, A. (2013) 'and the Modification Status of its Lipopolysaccharide', 47(6), pp. 897-908. doi: 10.1016/j.molcel.2012.07.017.Reciprocal.

Mao, Y., Ma, M., Wei, P., Zhang, P., Liu, L., Guan, T., Zhang, X. and Yi, T. (2020) 'A sensitive and rapid "off-on" fluorescent probe for the detection of esterase and its application in evaluating cell status and discrimination of living cells and dead cells', Analyst, 145(4), pp. 1408-1413. doi: 10.1039/c9an02085c.

Martínez, J. L., Baquero, F. and Andersson, D. I. (2007) 'Predicting antibiotic resistance', Nature Reviews Microbiology, 5(12), pp. 958-965. doi: 10.1038/nrmicro1796.

Nichol, D., Rutter, J., Bryant, C., Hujer, A. M., Lek, S., Adams, M. D., Jeavons, P., Anderson, A. R. A., Bonomo, R. A. and Scott, J. G. (2019) 'Antibiotic collateral sensitivity is contingent on the repeatability of evolution', Nature Communications, 10(1). doi: 10.1038/s41467-018-08098-6.

Olaitan, A. O., Morand, S. and Rolain, J. M. (2014) 'Mechanisms of polymyxin resistance: Acquired and intrinsic resistance in bacteria', Frontiers in Microbiology, 5(NOV), pp. 1-18. doi: 10.3389/fmicb.2014.00643.

Otasek, D., Morris, J. H., Bouças, J., Pico, A. R. and Demchak, B. (2019) 'Cytoscape Automation: Empowering workflow-based network analysis', Genome Biology. Genome Biology, 20(1), pp. 1-15. doi: 10.1186/s13059019-1758-4.

Pal, C., Maciá, M. D., Oliver, A., Schachar, I. and Buckling, A. (2007) 'Coevolution with viruses drives the evolution of bacterial mutation rates', Nature, 450(7172), pp. 1079-1081. doi: 10.1038/nature06350. Proshkin, S., Rahmouni, A. R. and Mironov, A. (2020) 'Elongation Linked references are available on JSTOR for this article : a R b T a c T a a d RNA P a a', 328(5977), pp. 504-508. 
Richter, M. F., Drown, B. S., Riley, A. P., Garcia, A., Shirai, T., Svec, R. L. and Hergenrother, P. J. (2017) 'Predictive compound accumulation rules yield a broad-spectrum antibiotic', Nature, 545(7654), pp. $299-304$. doi: $10.1038 /$ nature22308.

Rousseau, F., Serrano, L. and Schymkowitz, J. W. H. (2006) 'How evolutionary pressure against protein aggregation shaped chaperone specificity', Journal of Molecular Biology, 355(5), pp. 1037-1047. doi: 10.1016/j.jmb.2005.11.035.

RStudio Team (2020) RStudio: Integrated Development for R. RStudio, PBC, Boston, MA URL http://www.rstudio.com/., 2020.

Runti, G., Lopez Ruiz, M. del C., Stoilova, T., Hussain, R., Jennions, M., Choudhury, H. G., Benincasa, M., Gennaro, R., Beis, K. and Scocchi, M. (2013) 'Functional characterization of SbmA, a bacterial inner membrane transporter required for importing the antimicrobial peptide Bac7(1-35)', Journal of Bacteriology, 195(23), pp. 5343-5351. doi: 10.1128/JB.00818-13.

Schindelin, J., Arganda-Carreras, I., Frise, E., Kaynig, V., Longair, M., Pietzsch, T., Preibisch, S., Rueden, C., Saalfeld, S., Schmid, B., Tinevez, J. Y., White, D. J., Hartenstein, V., Eliceiri, K., Tomancak, P. and Cardona, A. (2012) 'Fiji: An open-source platform for biological-image analysis', Nature Methods, 9(7), pp. 676-682. doi: 10.1038/nmeth.2019.

Seiple, I. B., Zhang, Z., Jakubec, P., Langlois-Mercier, A., Wright, P. M., Hog, D. T., Yabu, K., Allu, S. R., Fukuzaki, T., Carlsen, P. N., Kitamura, Y., Zhou, X., Condakes, M. L., Szczypiński, F. T., Green, W. D. and Myers, A. G. (2016) 'A platform for the discovery of new macrolide antibiotics', Nature, 533, pp. 338-345. doi: 10.1038/nature17967.

Sergei Proshkin, Rachid Rahmouni, Alexander Mironov, and E. N. (2010) 'Polymerase in Transcription Elongation', Science, 328(5977), pp. 504-508. doi: 10.1126/science.1184939.Cooperation.

Sharma, O., Yamashita, E., Zhalnina, M. V., Zakharov, S. D., Datsenko, K. A., Wanner, B. L. and Cramer, W. A. (2007) 'Structure of the complex of the colicin E2 R-domain and its BtuB receptor: The outer membrane colicin translocon', Journal of Biological Chemistry, 282(32), pp. 23163-23170. doi: 10.1074/jbc.M703004200.

Simpson, B. W. and Trent, M. S. (2019) 'Pushing the envelope: LPS modifications and their consequences', Nature Reviews Microbiology, 17(7), pp. 403-416. doi: 10.1038/s41579-019-0201-x.

Sommer, M. O. A., Munck, C., Toft-Kehler, R. V. and Andersson, D. I. (2017) 'Prediction of antibiotic resistance: Time for a new preclinical paradigm?', Nature Reviews Microbiology, 15(11), pp. 689-696. doi: 10.1038/nrmicro.2017.75.

Soto, C. and Pritzkow, S. (2018) 'REVIEW ARTICLE | FOCUS diseases', 21(October).

Spohn, R., Daruka, L., Lázár, V., Martins, A., Vidovics, F., Grézal, G., Méhi, O., Kintses, B., Számel, M., Jangir, P. K., Csörg, B., Györkei, Á., Bódi, Z., Faragó, A., Bodai, L., Földesi, I., Kata, D., Maróti, G., Pap, B., Wirth, R., Papp, B. and Pál, C. (2019) 'Antimicrobial Peptides With Limited Resistance', (2019), pp. 1-13. doi: 10.1038/s41467019-12364-6.

Stokes, J. M., Yang, K., Swanson, K., Jaakkola, T. S., Barzilay, R. and Collins, J. J. (2020) 'Article A Deep Learning Approach', Cell, 180, pp. 688-702.

Suzuki, S., Horinouchi, T. and Furusawa, C. (2014) 'Prediction of antibiotic resistance by gene expression 
profiles', Nature Communications, 5. doi: 10.1038/ncomms6792.

Theuretzbacher, U., Outterson, K., Engel, A. and Karlén, A. (2020) 'The global preclinical antibacterial pipeline', Nature Reviews Microbiology, 18(5), pp. 275-285. doi: 10.1038/s41579-019-0288-0.

Tucker, A. T., Leonard, S. P., DuBois, C. D., Knauf, G. A., Cunningham, A. L., Wilke, C. O., Trent, M. S. and Davies, B. W. (2018) 'Discovery of Next-Generation Antimicrobials through Bacterial Self-Screening of SurfaceDisplayed Peptide Libraries', Cell. Elsevier Inc., 172(3), pp. 618-628.e13. doi: 10.1016/j.cell.2017.12.009.

Vecchi, G., Sormanni, P., Mannini, B., Vandelli, A., Tartaglia, G. G., Dobson, C. M., Hartl, F. U. and Vendruscolo, M. (2020) 'Proteome-wide observation of the phenomenon of life on the edge of solubility', Proceedings of the National Academy of Sciences of the United States of America, 117(2), pp. 1015-1020. doi: 10.1073/pnas.1910444117.

Wang, J., Williams, E. T., Bourgea, J., Wong, Y. N. and Patten, C. J. (2011) 'Characterization of recombinant human carboxylesterases: Fluorescein diacetate as a probe substrate for human carboxylesterase $2^{\prime}$, Drug Metabolism and Disposition, 39(8), pp. 1329-1333. doi: 10.1124/dmd.111.039628.

Wiener, M. C. and Horanyi, P. S. (2011) 'How hydrophobic molecules traverse the outer membranes of Gramnegative bacteria', Proceedings of the National Academy of Sciences of the United States of America, 108(27), pp. 10929-10930. doi: 10.1073/pnas.1106927108.

Woodford, N. and Ellington, M. J. (2007) 'The emergence of antibiotic resistance by mutation', Clinical Microbiology and Infection, 13(1), pp. 5-18. doi: 10.1111/j.1469-0691.2006.01492.x.

Yoshimura, Y., Lin, Y., Yagi, H., Lee, Y. H., Kitayama, H., Sakurai, K., So, M., Ogi, H., Naiki, H. and Goto, Y. (2012) 'Distinguishing crystal-like amyloid fibrils and glass-like amorphous aggregates from their kinetics of formation', Proceedings of the National Academy of Sciences of the United States of America, 109(36), pp. 14446-14451. doi: 10.1073/pnas.1208228109.

Zhang, Y. M. and Rock, C. O. (2008) 'Membrane lipid homeostasis in bacteria', Nature Reviews Microbiology, 6(3), pp. 222-233. doi: 10.1038/nrmicro1839. 


\section{Wu et al, Figure 1}
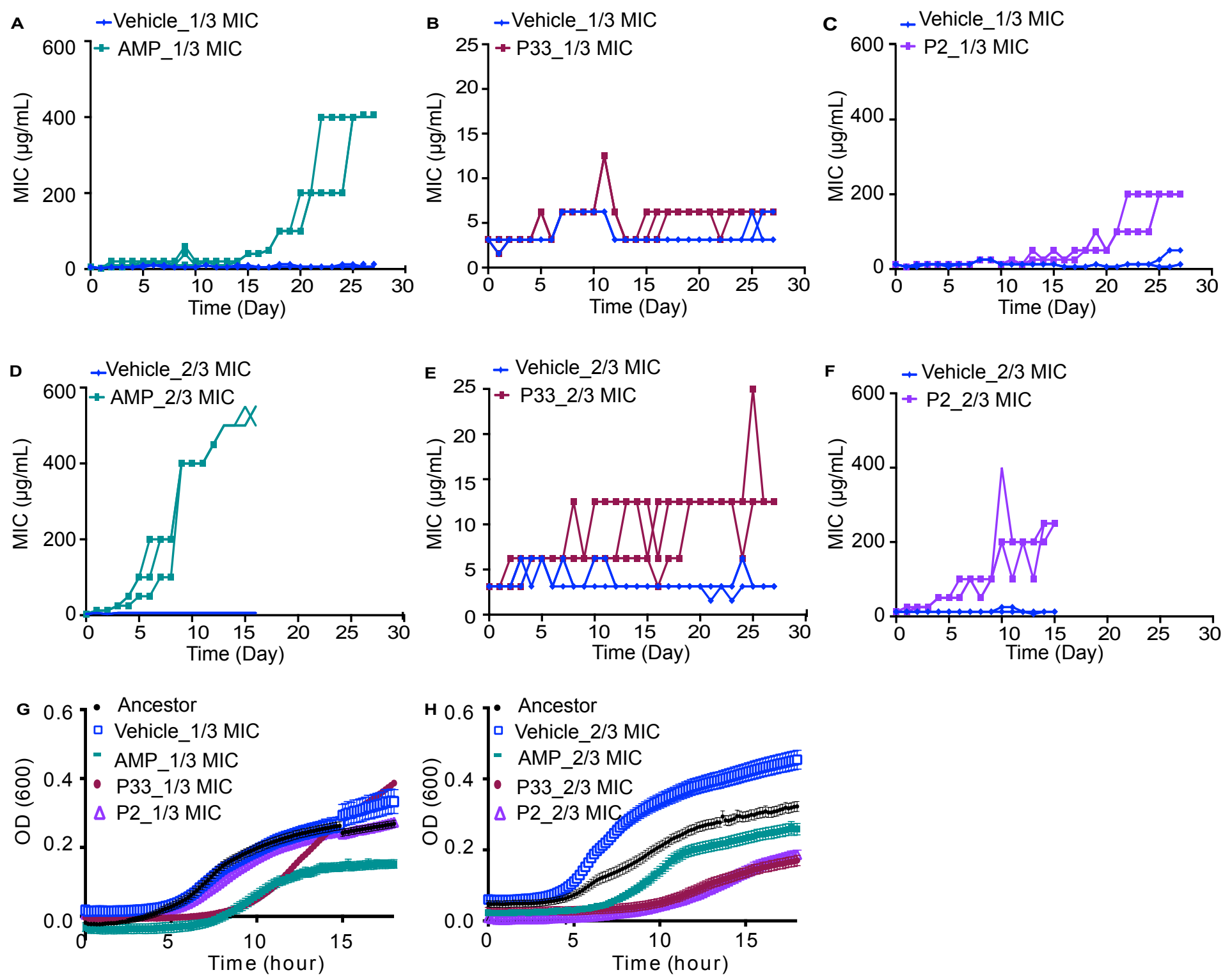


\section{Wu et al, Figure 2}
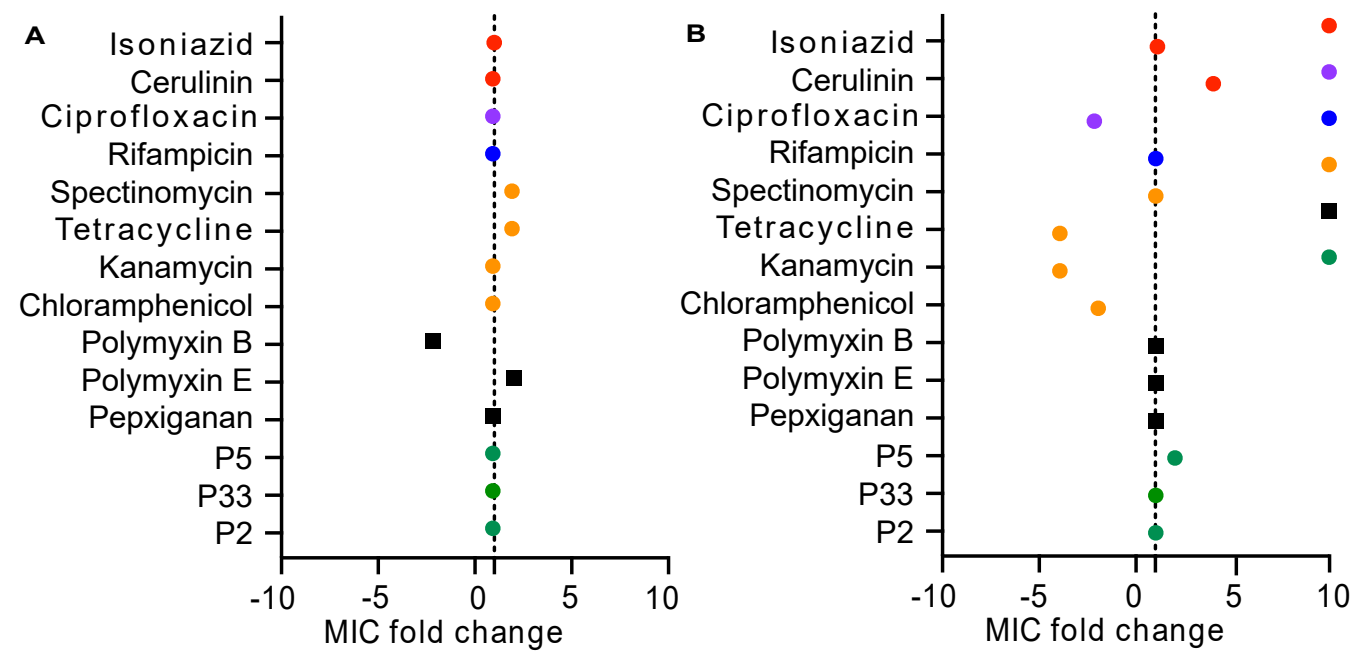

- Fatty acid synthesis inhibitor

- Cell division inhibitor

- RNA synthesis inhibitor

Protein synthesis inhibitor

- CAMP

Pept-in

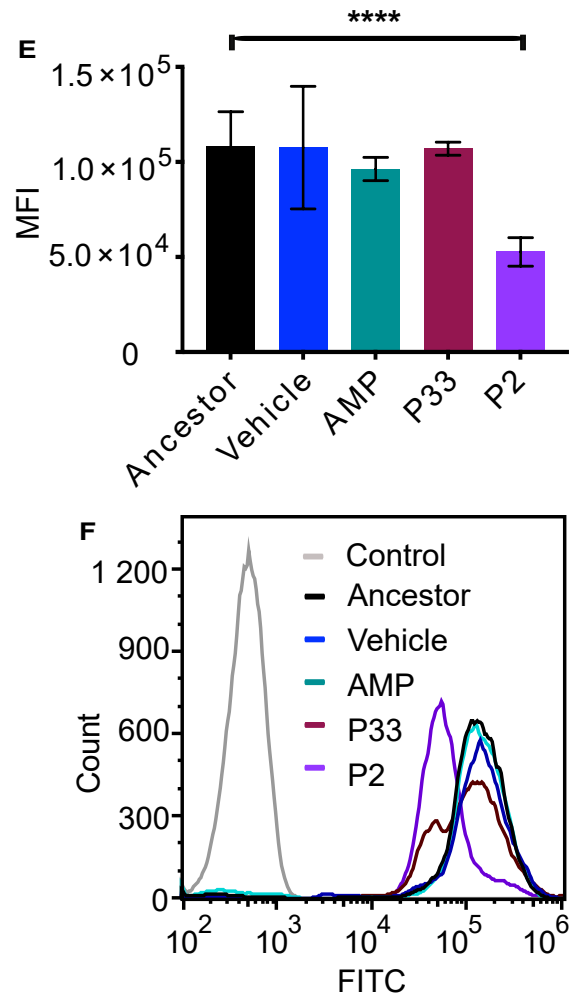

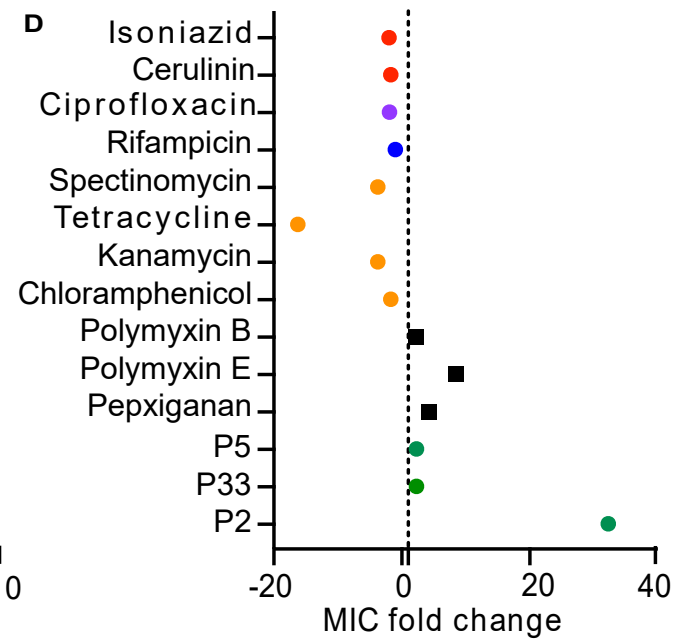

0

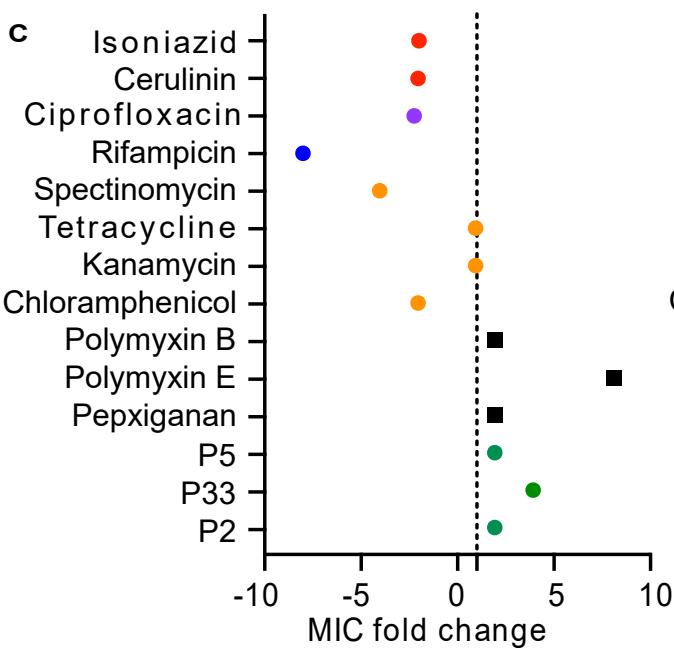


Wu et al, Figure 3

- Ancestor

- -Day 13_Vehicle

-Day 27_Vehicle o

$\_$Day 13_AMP

--Day 27_AMP

- Day 13_P33

-- Day 27_P33

$\rightarrow$ D ay 13 _P 2

-D ay 27 -P2

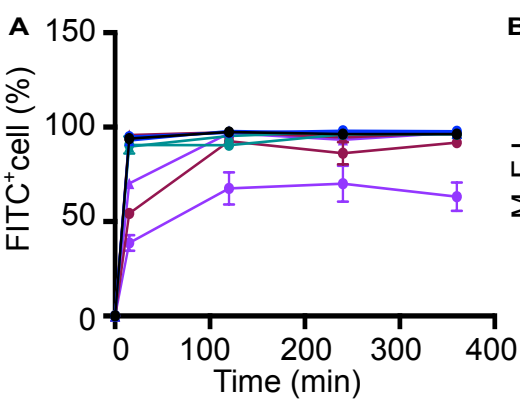

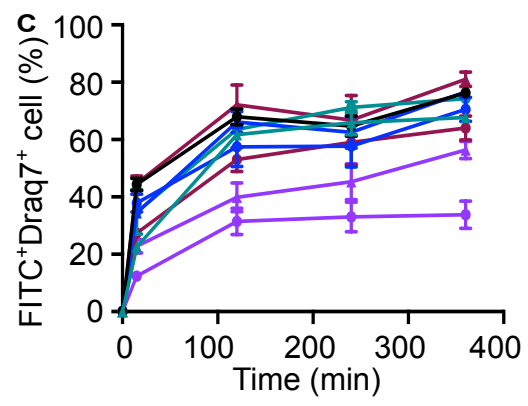

P2
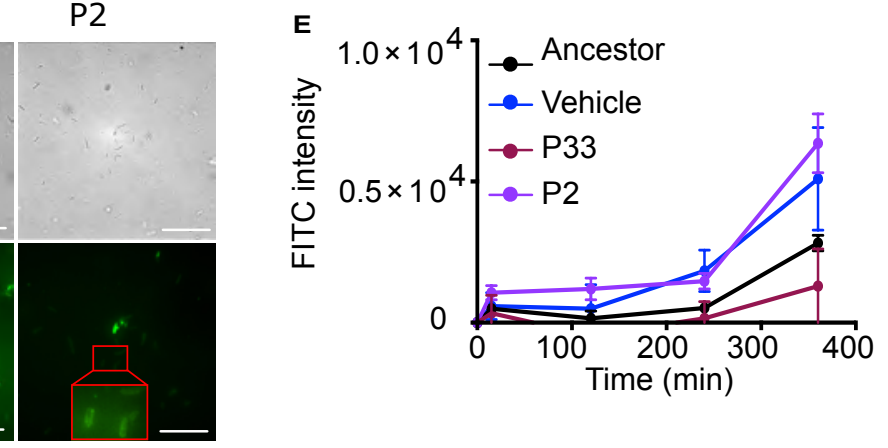

FIIC

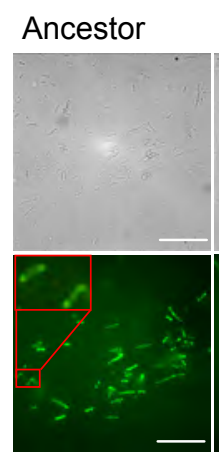

Vehicle

AMP

D

Bright
field

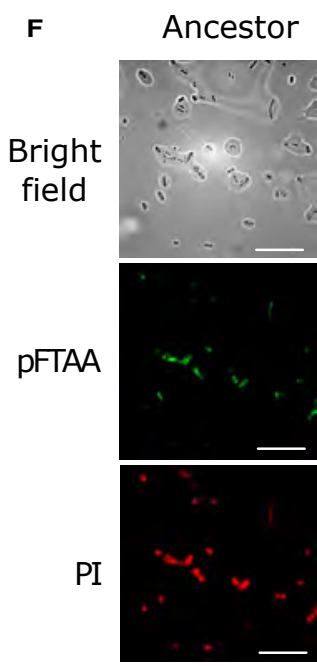

$\mathrm{P} 2$

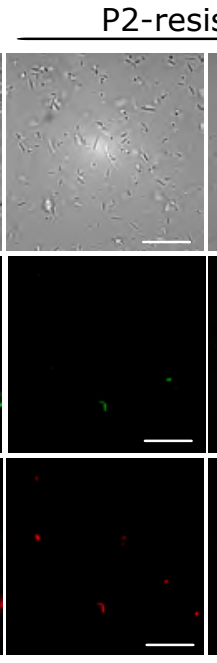

P2
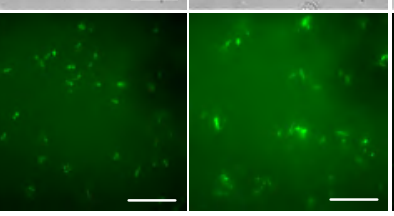

$6.5 \mu \mathrm{g} / \mathrm{mL} \quad 6.5 \mu \mathrm{g} / \mathrm{mL} \quad 200 \mu \mathrm{g} / \mathrm{mL}$
G Ancestor P2-resistant
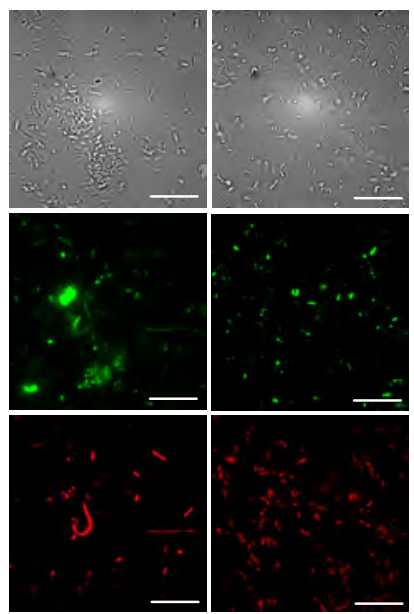

P33

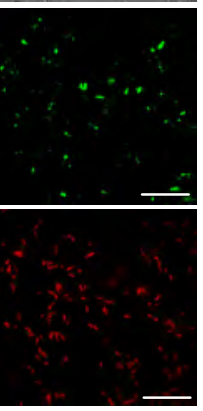

P33

$6.5 \mu \mathrm{g} / \mathrm{mL} \quad 6.5 \mu \mathrm{g} / \mathrm{mL}$

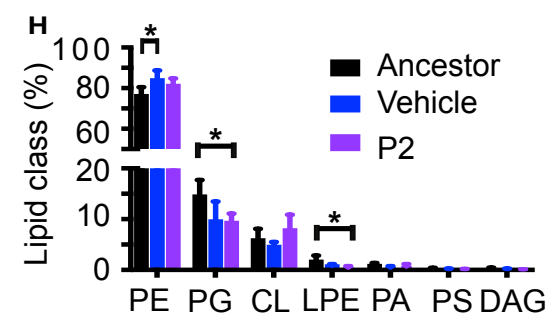

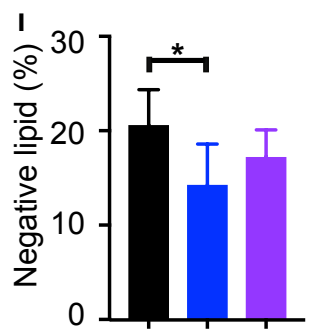

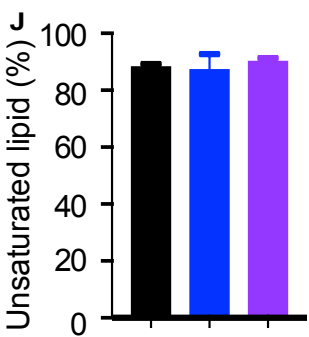

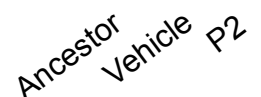

0

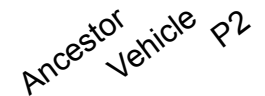


A Extracellular polysaccharide biosynthetic processLipid A biosynthetic process Biofilm formation
Defense response to virus
Resistance to acid stress Resistance to acid stress Anaerobic respiration Sulfate transportIron uptake-

Biotin biosynthetic process Branched-chain amino acid metabolic process Thiamine-containing compound metabolic process Monocarboxylic acid catabolic process 6-sulfoquinovose(1-) catabolic processL-ascorbic acid metabolic process
Upregulation

Downregulation

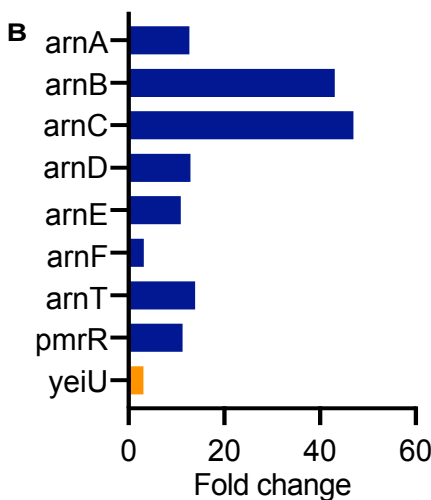


Wu et al, Figure 5
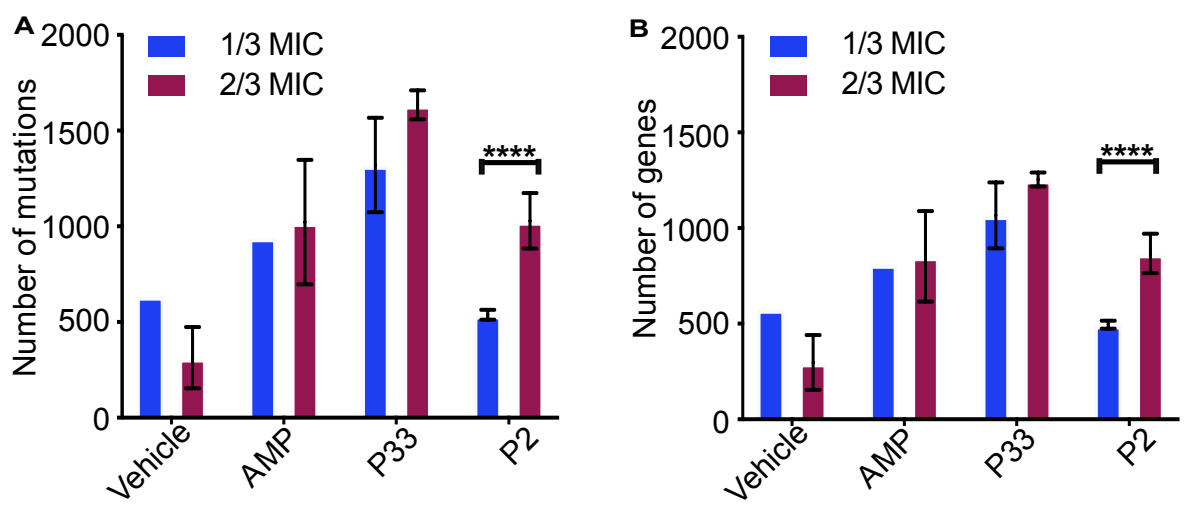

C
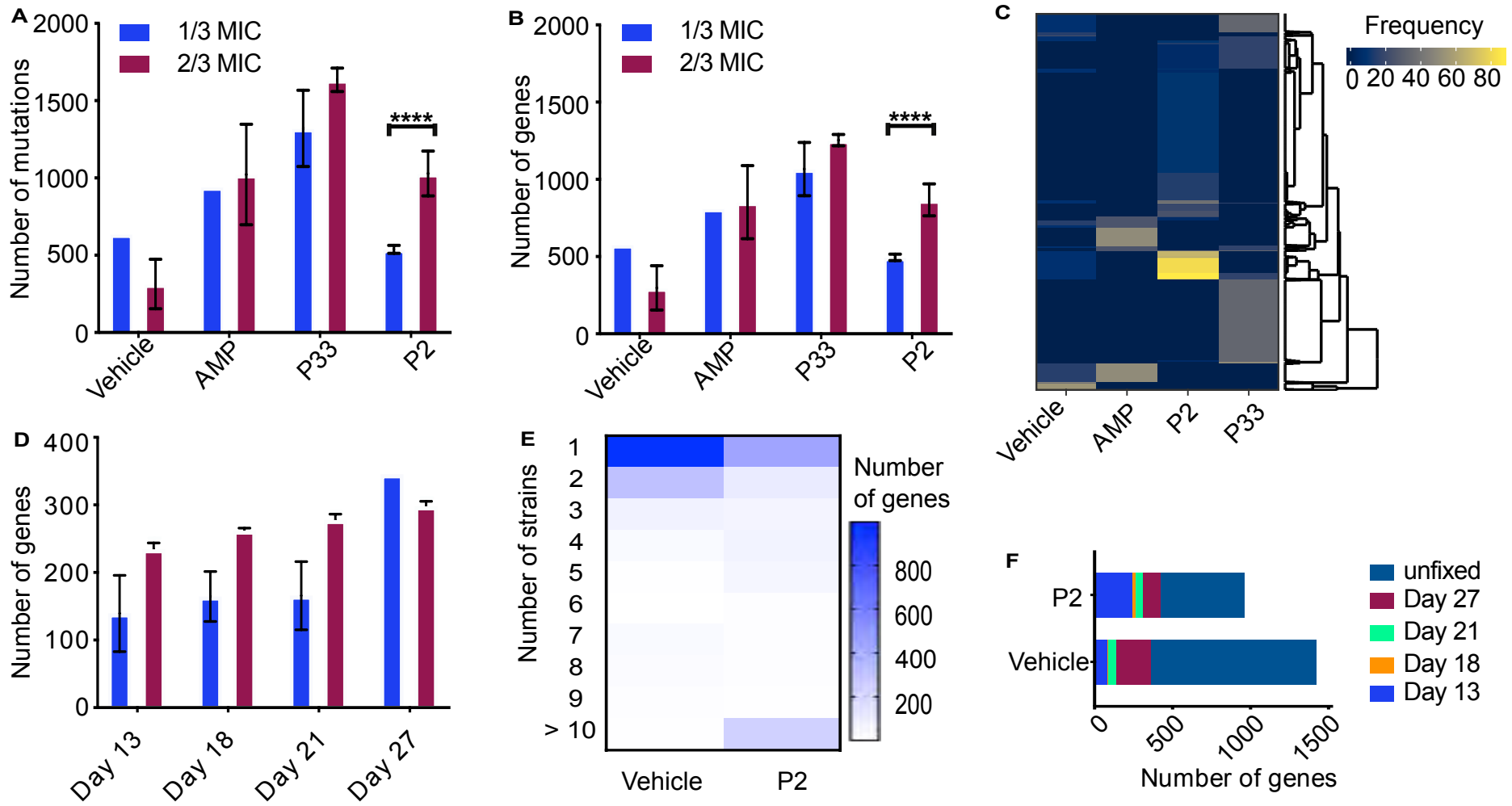

unfixed

Day 27

Day 21

Day 18

Day 13

Number of genes

H

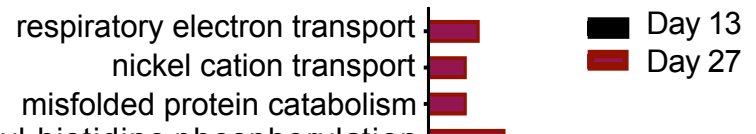
Day 27

G gluconate transport

phosphorelay signal transduction

fatty acid beta-oxidation cell adhesion

lipid homeostasis biotin biosynthetic nucleotide-excision repair

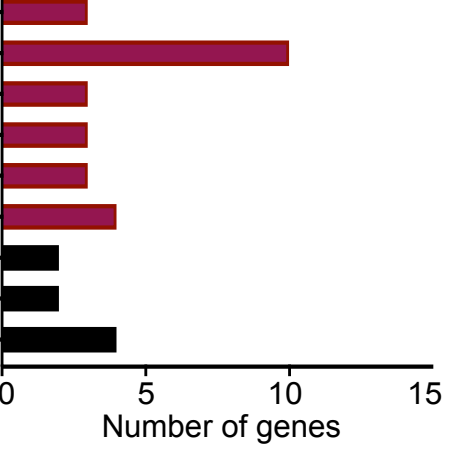
peptidyl-histidine phosphorylation dipeptide transport cobalt ion transport protein secretion cellular amino acid metabolism protein transport nucleic acid hydrolysis transmembrane transport pilus assembly peptide transport proteolysis tricarboxylic acid cycle

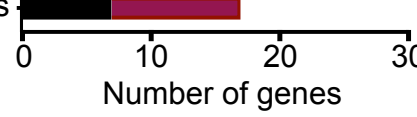



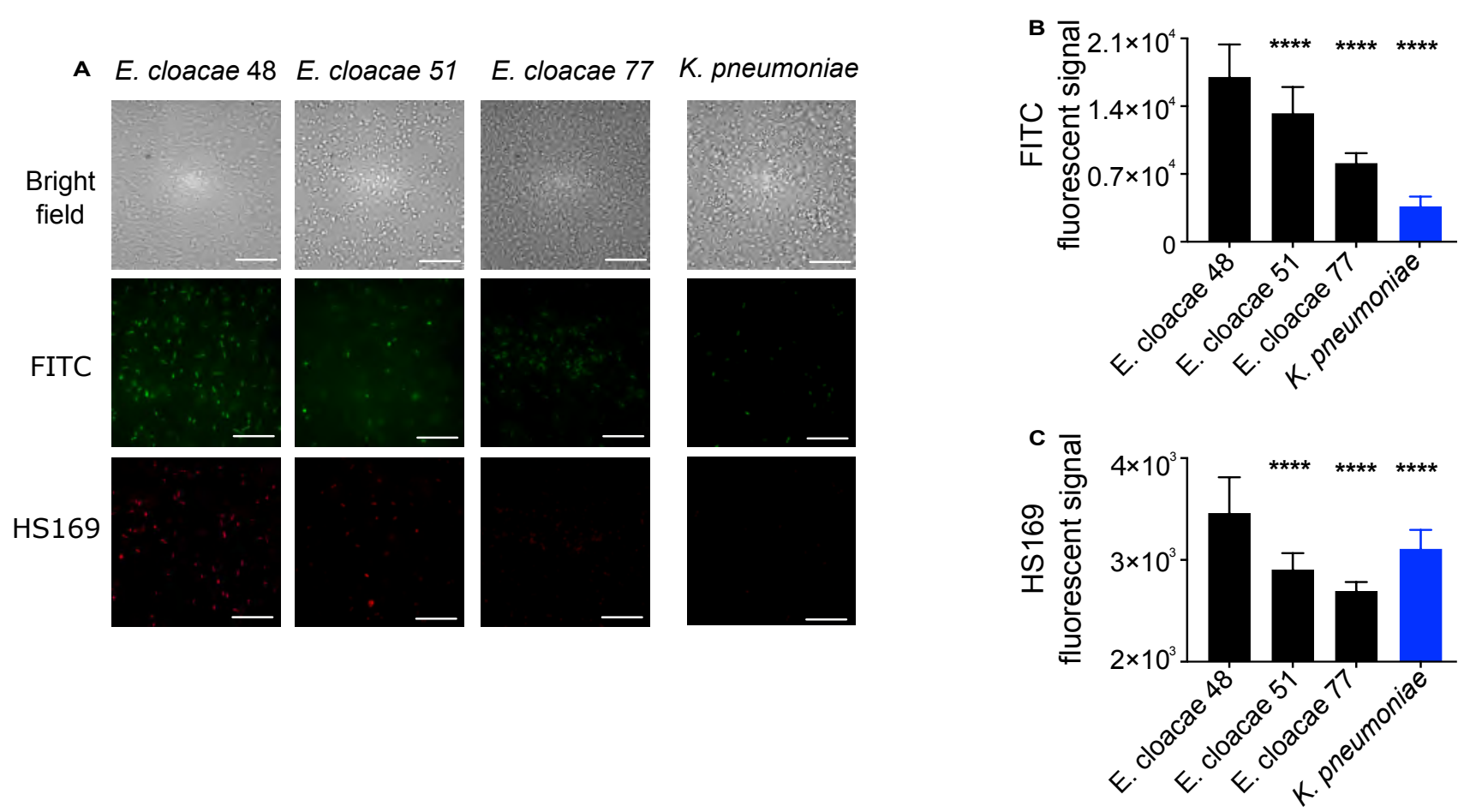

D E. cloacae 48 E. cloacae 51 E. cloacae $77 \quad$ K. pneumoniae
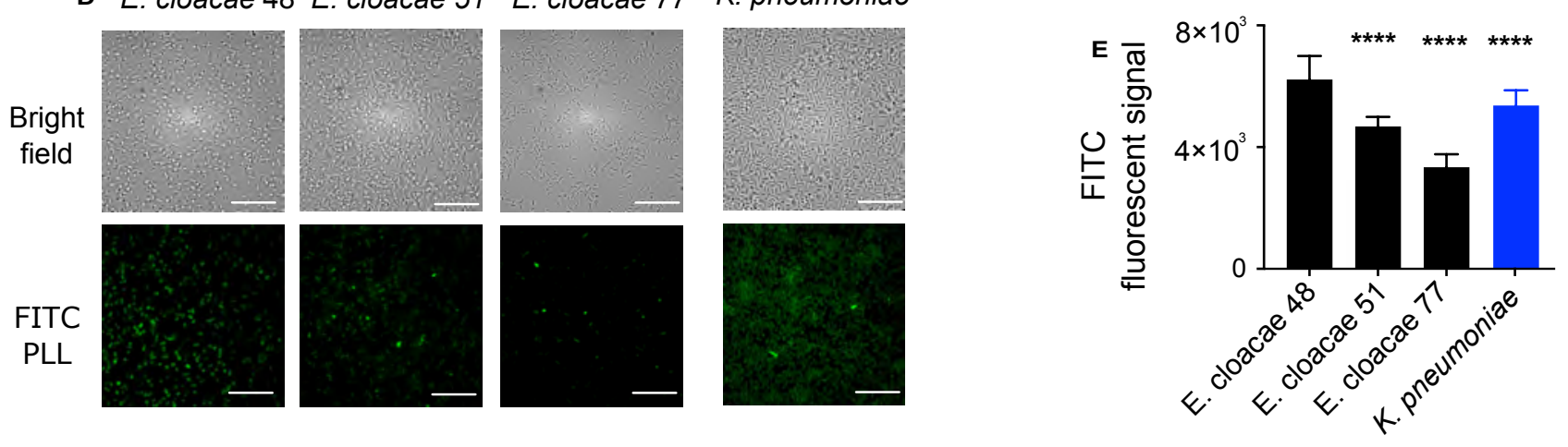


\section{Supplementary information}

Investigating the mechanism of action of aggregation-inducing antimicrobial Pept-ins

Guiqin Wu $\mathbf{u}^{1,2}$, Laleh Khodaparast ${ }^{1,2}$, Ladan Khodaparast ${ }^{1,2}$, Matthias De Vleeschouwer ${ }^{1,2}$, Joëlle Housmans ${ }^{1,2}$, Bert Houben ${ }^{1,2}$, Joost Schymkowitz ${ }^{1,2,3, *}$ and Frederic Rousseau ${ }^{1,2, *}$

${ }^{1}$ Switch Laboratory, VIB Center for Brain and Disease Research, Herestraat 49, 3000 Leuven, Belgium.

${ }^{2}$ Switch Laboratory, Department of Cellular and Molecular Medicine, KU Leuven, Herestraat 49, 3000 Leuven, Belgium.

${ }^{3}$ Lead contact

* to whom correspondence should be addressed: joost.schymkowitz@kuleuven.be or

frederic.rousseau@kuleuven.be 

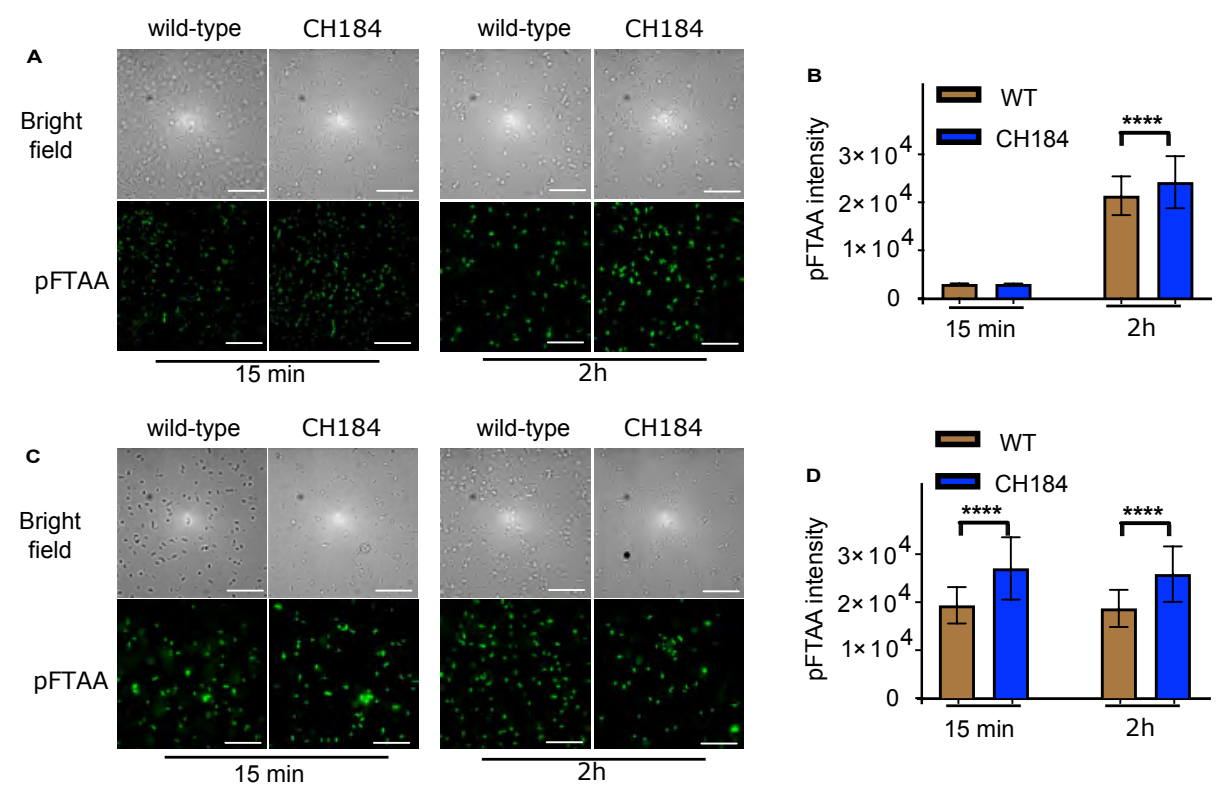

Figure S1. IB formation of $E$. coli wild-type (WT) and $\mathrm{CH} 184$ mutant strain upon Pept-in treatment, related to Figure 4.

A. SIM images of E. coli WT and CH184 mutant strain upon P2 treatment at $12.5 \mu \mathrm{g} / \mathrm{mL}$ for $2 \mathrm{~h}$. Amyloid-specific dye pFTAA was incubated with bacteria for 1.5 h. B. Fluorescent intensity quantification of pFTAA of images shown in Fig A. C. SIM images of E. coli WT and CH184 mutant strain upon P33 treatment at $6.5 \mu \mathrm{g} / \mathrm{mL}$ for 2 h. Amyloidspecific dye pFTAA was incubated with bacteria for 1.5 h. B. Fluorescent intensity quantification of pFTAA of images shown in Fig C. Scale bar: $10 \mu \mathrm{m}$. Error bars represent SD, two-tailed student t test was performed for calculating statistical significance $(\mathrm{n}=$ at least 3$)$.

Table S1. P2 and P33 MIC in wild-type and CH184 mutant strain, related to Figure S1.

\begin{tabular}{|l|l|l|}
\hline Strain & P2 MIC $(\mu \mathrm{g} / \mathrm{mL})$ & P33 MIC $(\mu \mathrm{g} / \mathrm{mL})$ \\
\hline wild-type & 12.5 & 6.5 \\
\hline CH184 & 12.5 & 3.2 \\
\hline
\end{tabular}

Table S2. Antibiotics which are used to determine the collateral-sensitivity and cross-resistance profile of evolved strains, related to Figure 2.

\begin{tabular}{|l|l|}
\hline Name & Antibiotic class \\
\hline P2 & Aggregation-inducing Pept-in \\
\hline P33 & Aggregation-inducing Pept-in \\
\hline P5 & Aggregation-inducing Pept-in \\
\hline Pexiganan & CAMP \\
\hline Polymyxin B & CAMP \\
\hline Polymyxin E & CAMP \\
\hline Chloramphenicol & Protein synthesis inhibitor \\
\hline Kanamycin & Protein synthesis inhibitor \\
\hline Tetracycline & Protein synthesis inhibitor \\
\hline Spectinomycin & Protein synthesis inhibitor \\
\hline Rifampicin & RNA synthesis inhibitor \\
\hline Ciprofloxacin & Cell division inhibitor \\
\hline Cerulinin & Fatty acid synthesis inhibitor \\
\hline
\end{tabular}


Table S3. Downregulated transporters, related to Figure 4.

\begin{tabular}{|l|l|l|}
\hline Gene name & Fold of downregulation & Function \\
\hline btuB & 2.1 & vitamin B12 outer membrane transporter \\
\hline cysA & 4.9 & sulfate transporter subunit \\
\hline cysU & 3.5 & sulfate ABC transporter permease \\
\hline sbp & 3.2 & sulfate transporter subunit \\
\hline fadL & 2.2 & long-chain fatty acid outer membrane transporter \\
\hline ansP & 2.4 & L-asparagine transporter (ansP) \\
\hline aroP & 2.1 & aromatic amino acid transporter (aroP) \\
\hline gltJ & 2.6 & glutamate/aspartate ABC transporter permease (gltJ) \\
\hline hisJ & 3 & histidine ABC transporter periplasmic binding protein (hisJ) \\
\hline macA & 2.1 & macrolide transporter membrane fusion protein component \\
\hline macB & 2.2 & macrolide ABC transporter peremase/ATPase (macB) \\
\hline mgtA & 4.2 & magnesium transporter (mgtA) \\
\hline nikB & 2.9 & nickel ABC transporter permease (nikB) \\
\hline phnK & 3.8 & carbon-phosphorus lyase complex subunit \\
\hline pitA & 2.3 & phosphate transporter, low-affinity; tellurite importer (pitA) \\
\hline tauA & 2.2 & taurine ABC transporter periplasmic binding protein (tauA) \\
\hline tyrP & 4.5 & tyrosine transporter (tyrP) \\
\hline ybbW & 3.1 & putative allantoin transporter (ybbW) \\
\hline ygiS & 2.5 & putative ABC transporter permease (ygiS) \\
\hline yifK & 2.1 & putative APC family amino acid transporter (yifK) \\
\hline
\end{tabular}

Table S4. P2 MIC of knock out strains, related to Figure 5.

\begin{tabular}{|l|l|l|l|}
\hline $\begin{array}{l}\text { WT or knock out } \\
\text { Strain }\end{array}$ & MIC $(\mu \mathrm{g} / \mathrm{mL})$ & Function & $\begin{array}{l}\text { dN/dS } \\
\text { resistant }\end{array}$ \\
\hline$\Delta$ macA* & 12.5 & macrolide transporter membrane fusion protein & 80.95 \\
\hline$\Delta$ macB* & 12.5 & macrolide ABC transporter peremase/ATPase & 19.83 \\
\hline$\Delta$ ybhD & 12.5 & putative DNA-binding transcriptional regulator & 95.24 \\
\hline$\Delta$ clpA & 12.5 & chaperone activity & 95.24 \\
\hline$\Delta$ ushA & 12.5 & UDP-sugar hydrolase & 95.24 \\
\hline$\Delta$ endA & 12.5 & DNA-specific endonuclease I & 90.48 \\
\hline$\Delta$ oppD & 12.5 & oligopeptide ABC transporter ATPase & 85.71 \\
\hline$\Delta$ paaB & 12.5 & putative ring 1,2-phenylacetyl-CoA epoxidase subunit & 85.71 \\
\hline$\Delta$ fliF & 12.5 & flagellar basal-body MS-ring and collar protein & 85.71 \\
\hline$\Delta$ purM & 12.5 & phosphoribosylaminoimidazole synthetase & 85.71 \\
\hline$\Delta$ atpF & 12.5 & FO sector of membrane-bound ATP synthase & 85.71 \\
\hline$\Delta$ sufC & 12.5 & SufBCD Fe-S cluster assembly scaffold protein & 85.71 \\
\hline$\Delta$ lon & 12.5 & DNA-binding ATP-dependent protease La & 80.95 \\
\hline$\Delta$ tyrA & 12.5 & fused chorismate mutase T & 80.95 \\
\hline$\Delta$ metB & 12.5 & cystathionine gamma-synthase, PLP-dependent & 76.19 \\
\hline$\Delta$ cheR & 12.5 & protein-glutamate methyltransferase & 76.19 \\
\hline$\Delta$ sdaA & 12.5 & L-serine dehydratase 1 & 71.43 \\
\hline$\Delta$ kbl & 12.5 & glycine C-acetyltransferase & 71.43 \\
\hline$\Delta$ yiaU & 12.5 & putative DNA-binding transcriptional regulator & 66.67 \\
\hline$\Delta$ yfhQ & 12.5 & tRNA & 66.67 \\
\hline$\Delta$ ypjL & 12.5 & Predicted inner membrane protein & 66.67 \\
\hline$\Delta$ polB & 12.5 & DNA polymerase II & 38.10 \\
\hline$\Delta$ ppx & 12.5 & exopolyphosphatase & 38.10 \\
\hline & & & \\
\hline
\end{tabular}




\begin{tabular}{|c|c|c|c|}
\hline$\Delta \mathrm{skp}$ & 12.5 & periplasmic chaperone & 33.33 \\
\hline$\Delta \mathrm{ynfM}$ & 12.5 & putative arabinose efflux transporter & 33.33 \\
\hline$\Delta$ fiu & 12.5 & catecholate siderophore receptor & 33.33 \\
\hline$\Delta$ yadC & 12.5 & putative fimbrial-like adhesin protein & 28.57 \\
\hline$\Delta$ wcaE & 12.5 & putative glycosyl transferase & 28.57 \\
\hline$\Delta y c c z$ & 12.5 & Outer membrane lipoprotein & 28.57 \\
\hline$\Delta \mathrm{lptB}$ & 12.5 & lipopolysaccharide export ABC transporter ATPase & 23.81 \\
\hline$\Delta$ tehA & 12.5 & potassium-tellurite ethidium and proflavin transporter & 23.81 \\
\hline$\Delta$ epd & 12.5 & D-erythrose 4-phosphate dehydrogenase & 23.81 \\
\hline$\Delta \mathrm{rcnA}$ & 12.5 & $\begin{array}{l}\text { membrane protein conferring nickel and cobalt } \\
\text { resistance }\end{array}$ & 23.81 \\
\hline$\Delta$ yoaB & 12.5 & putative reactive intermediate deaminase & 23.81 \\
\hline$\Delta \mathrm{yfbT}$ & 12.5 & sugar phosphatas & 23.81 \\
\hline$\triangle \mathrm{oppF}$ & 12.5 & oligopeptide ABC transporter ATPase & 19.05 \\
\hline$\Delta \operatorname{manY}$ & 12.5 & mannose-specific enzyme IIC component of PTS & 19.05 \\
\hline$\Delta$ yejE & 12.5 & microcin C ABC transporter permease & 19.05 \\
\hline$\Delta y d h O$ & 12.5 & Endopeptidase & 19.05 \\
\hline$\Delta r n b$ & 12.5 & ribonuclease II & 19.05 \\
\hline$\Delta$ lys $C$ & 12.5 & Iysine-sensitive aspartokinase 3 & 14.29 \\
\hline$\Delta$ yegH & 12.5 & inner membrane protein & 14.29 \\
\hline$\Delta$ yecC & 12.5 & putative $A B C$ transporter ATPase & 9.52 \\
\hline$\Delta$ tufA & 12.5 & translation elongation factor EF-Tu 1 & 9.52 \\
\hline$\Delta$ lys A & fphnK & diaminopimelate decarboxylase, PLP-binding & 4.96 \\
\hline$\Delta$ proX & 12.5 & glycine betaine/proline $\mathrm{ABC}$ transporter & 4.76 \\
\hline$\Delta$ fliY & 12.5 & cystine transporter subunit & 4.76 \\
\hline$\Delta$ metL & 12.5 & Bifunctional aspartokinase/homoserine dehydrogenase 2 & 4.13 \\
\hline$\Delta$ hycD & 12.5 & hydrogenase 3 , membrane subunit & 4.13 \\
\hline$\Delta$ yehY & 12.5 & putative $A B C$ transporter permease & 3.31 \\
\hline$\Delta$ ydiO & 12.5 & putative acyl-CoA dehydrogenase & 3.31 \\
\hline$\Delta r f a E$ & 12.5 & $\# N / A$ & 3.17 \\
\hline$\Delta$ purF & 12.5 & amidophosphoribosyltransferase & 2.71 \\
\hline$\triangle \mathrm{oppB}$ & 12.5 & oligopeptide $A B C$ transporter permease & 2.49 \\
\hline$\Delta \operatorname{din} \mathrm{D}$ & 12.5 & DNA damage-inducible protein & 2.48 \\
\hline$\Delta$ fryC & 12.5 & putative enzyme IIC component of PTS & 2.48 \\
\hline$\Delta \operatorname{lsrB}$ & 12.5 & autoinducer 2-binding protein & 2.26 \\
\hline$\Delta$ aidB & 12.5 & DNA alkylation damage repair protein & 1.87 \\
\hline$\Delta$ yfeA & 12.5 & putative diguanylate cyclase & 1.81 \\
\hline$\Delta \mathrm{cydD}$ & 12.5 & glutathione/cysteine $\mathrm{ABC}$ transporter export permease & 1.65 \\
\hline$\Delta$ ProY & 12.5 & proline-specific permease & 1.46 \\
\hline$\triangle$ PotABCD & 12.5 & putrescine $A B C$ transporter & \\
\hline$\triangle$ PotFGHI & 12.5 & putrescine $A B C$ transporter & \\
\hline$\triangle$ cysA* & 25 & sulfate/thiosulfate transporter subunit & 0.00 \\
\hline$\Delta$ cysu* & 25 & sulfate/thiosulfate $A B C$ transporter permease & 38.10 \\
\hline$\Delta g \mid t f^{*}$ & 25 & glutamate/aspartate $A B C$ transporter permease & 8.60 \\
\hline$\Delta$ cysP & 25 & thiosulfate-binding protein & 9.52 \\
\hline$\Delta$ cysW & 25 & sulfate/thiosulfate $A B C$ transporter permease & 9.52 \\
\hline$\Delta \mathrm{ddpB}$ & 25 & D,D-dipeptide $A B C$ transporter permease & 19.05 \\
\hline$\Delta \mathrm{ddpC}$ & 25 & $\mathrm{D}, \mathrm{D}$-dipeptide $\mathrm{ABC}$ transporter permease & 0.00 \\
\hline$\Delta \mathrm{ddpD}$ & 25 & D,D-dipeptide ABC transporter ATPase & 0.05 \\
\hline$\Delta \mathrm{ddpF}$ & 25 & D,D-dipeptide ABC transporter ATPase & 80.95 \\
\hline$\Delta$ deoA & 25 & thymidine phosphorylase & 23.81 \\
\hline$\Delta \mathrm{dppA}$ & 25 & $\begin{array}{l}\text { dipeptide/heme } A B C \text { transporter periplasmic binding } \\
\text { protein }\end{array}$ & 14.88 \\
\hline
\end{tabular}




\begin{tabular}{|c|c|c|c|}
\hline$\Delta \mathrm{dppB}$ & 25 & dipeptide/heme $\mathrm{ABC}$ transporter permease & 0.83 \\
\hline$\triangle \mathrm{dppC}$ & 25 & dipeptide/heme $A B C$ transporter permease & 0.00 \\
\hline$\Delta \mathrm{dppD}$ & 25 & dipeptide/heme ABC transporter ATPas & 4.76 \\
\hline$\Delta \mathrm{dppF}$ & 25 & dipeptide/heme ABC transporter ATPas & 16.74 \\
\hline$\triangle$ potA & 25 & spermidine/putrescine ABC transporter ATPase & 0.31 \\
\hline$\Delta$ potB & 25 & spermidine/putrescine $A B C$ transporter permease & 4.76 \\
\hline$\Delta$ potC & 25 & spermidine/putrescine $A B C$ transporter permease & 9.52 \\
\hline$\Delta$ potF & 25 & putrescine $A B C$ transporter periplasmic binding protein & 0.83 \\
\hline$\Delta$ potG & 25 & putrescine $A B C$ transporter ATPase & 1.66 \\
\hline$\Delta$ potl & 25 & putrescine $A B C$ transporter permease & 9.52 \\
\hline$\Delta \mathrm{amn}$ & 25 & AMP nucleosidase & 38.10 \\
\hline$\Delta \operatorname{exbB}$ & 25 & membrane spanning protein in TonB-ExbB-ExbD complex & 28.57 \\
\hline$\Delta$ pldA & 25 & outer membrane phospholipase A & 23.81 \\
\hline$\Delta$ cueR & 25 & copper-responsive regulon transcriptional regulator & 19.05 \\
\hline$\Delta$ pntA & 25 & pyridine nucleotide transhydrogenase, alpha subunit & 19.05 \\
\hline$\Delta$ ssuA & 25 & aliphatic sulfonate $A B C$ transporter & 19.05 \\
\hline$\Delta$ tatE & 25 & TatABCE protein translocation system subunit & 19.05 \\
\hline$\Delta \mathrm{tdh}$ & 25 & L-threonine 3-dehydrogenase, NAD & 19.05 \\
\hline$\Delta$ yjgJ & 25 & Predicted transcriptional regulator & 19.05 \\
\hline$\Delta \operatorname{modB}$ & 25 & molybdate $A B C$ transporter permease & 14.05 \\
\hline$\Delta \mathrm{pstS}$ & 25 & phosphate $A B C$ transporter periplasmic binding protein & 9.52 \\
\hline$\Delta y h d z$ & 25 & putative amino acid $A B C$ transporter ATPase & 9.52 \\
\hline$\triangle$ znuA & 25 & zinc $A B C$ transporter periplasmic binding protein & 9.52 \\
\hline$\Delta$ ais & 25 & putative LPS core heptose & 4.76 \\
\hline$\Delta$ araH & 25 & L-arabinose $A B C$ transporter permease & 4.76 \\
\hline$\Delta \operatorname{argT}$ & 25 & lysine/arginine/ornithine transporter subunit & 4.76 \\
\hline$\Delta$ fecE & 25 & ferric citrate $A B C$ transporter ATPase & 4.76 \\
\hline$\Delta$ fepB & 25 & $\begin{array}{l}\text { ferrienterobactin } A B C \text { transporter periplasmic binding } \\
\text { protein }\end{array}$ & 4.76 \\
\hline$\Delta \mathrm{g} \mid \mathrm{mM}$ & 25 & phosphoglucosamine mutase & 4.76 \\
\hline$\Delta \mathrm{glnH}$ & 25 & glutamine transporter subunit & 4.76 \\
\hline$\Delta$ lepA & 25 & back-translocating elongation factor EF4, GTPase & 4.76 \\
\hline$\Delta$ malE & 25 & maltose transporter subunit & 4.76 \\
\hline$\Delta \operatorname{modC}$ & 25 & molybdate ABC transporter ATPase & 4.76 \\
\hline$\triangle \mathrm{rfbA}$ & 25 & glucose-1-phosphate thymidylyltransferase & 4.76 \\
\hline$\Delta x y l F$ & 25 & D-xylose transporter subunit & 4.76 \\
\hline$\Delta$ malk & 25 & maltose $A B C$ transportor ATPase & 4.13 \\
\hline$\Delta$ xapB & 25 & xanthosine transporter & 2.26 \\
\hline$\Delta y c j W$ & 25 & Lacl family putative transcriptional repressor & 1.87 \\
\hline$\Delta$ tors & 25 & hybrid sensory histidine kinase & 1.81 \\
\hline$\Delta$ yecs & 25 & $A B C$ family putative inner membrane permease & 1.65 \\
\hline$\Delta \mathrm{mglB}$ & 25 & methyl-galactoside transporter subunit & 0.83 \\
\hline$\Delta$ yojl & 25 & microcin J25 efflux $A B C$ transporter permease & 0.83 \\
\hline$\Delta \mathrm{gspH}$ & 25 & putative general secretory pathway component, cryptic & 0.00 \\
\hline$\Delta$ hcab & 25 & $\begin{array}{l}\text { 2,3-dihydroxy-2,3-dihydrophenylpropionate } \\
\text { dehydrogenase }\end{array}$ & 0.00 \\
\hline$\Delta$ nikE & 25 & nickel $A B C$ transporter ATPase & 0.00 \\
\hline
\end{tabular}

* Expression was downregulated in P2-resistant cells compared to ancestor cells.

Table S5. P2 MIC in different clinical isolates, related to Figure 6.

\begin{tabular}{|l|l|}
\hline Strain & P2 MIC $(\mu \mathrm{g} / \mathrm{mL})$ \\
\hline
\end{tabular}




\begin{tabular}{|l|l|}
\hline E. cloacae $48^{*}$ & 25 \\
\hline E. cloacae $51^{*}$ & $>100$ \\
\hline E. cloacae $77^{*}$ & $>100$ \\
\hline K. pneumoniae & $>100$ \\
\hline
\end{tabular}

* Different isolates of the same strain 